\title{
Rhodanine-based nonfullerene acceptors for organic solar cells
}

\author{
Hongtao Liu ${ }^{1}$, Zhong'an $\mathrm{Li}^{1^{*}}$ and Dongbing Zhao ${ }^{2^{*}}$
}

\begin{abstract}
Significant progress on the development of nonfullerene acceptors (NFAs) for organic solar cells (OSCs) has been made in the past several years, and the power conversion efficiency (PCE) exceeding $17 \%$ has been already realized based on a tandem non-fullerene device. To date, NFAs with a linearly fused acceptor-donor-acceptor (A-D-A) structure are of great interest, due to their attracting synthetic flexibility and high photovoltaic performance. Rhodanine is one of the most studied electron-withdrawing moieties to construct such A-D-A type NFAs, and the resulting single-junction OSCs have produced PCEs of $\sim \mathbf{1 0} \%$. More interestingly, those rhodanine-based NFAs have demonstrated a particularly excellent compatibility with well-known P3HT donor, enabling respectable PCEs over 7\%. Thus in this review, we summarize the important advances on rhodanine-based NFAs with a main focus on discussing the molecular design strategies, providing a better understanding of the structure-property relationship for those rhodanine-based NFAs.
\end{abstract}

Keywords: organic solar cells, non-fullerene acceptors, rhodanine

\section{INTRODUCTION}

Photoinduced charge transfer between p-type and n-type organic semiconductors (donors and acceptors) is the basic process for organic solar cells (OSCs) [1,2]. Since buckminsterfullerene $\left(\mathrm{C}_{60}\right)$ and its derivatives were introduced as the acceptors to blend with polymer donor MEH-PPV [2], OSCs have been dominated by fullerene acceptors for nearly two decades, such as $[6,6]-$ phenylC $_{61}{ }^{-}$ butyric acid methyl ester $\left(\mathrm{PC}_{61} \mathrm{BM}\right)$ and $[6,6]$-phenyl- $\mathrm{C}_{71^{-}}$butyric acid methyl ester $\left(\mathrm{PC}_{71} \mathrm{BM}\right)$. Currently, the maximum power conversion efficiencies (PCEs) of single- junction fullerene-based OSCs have been already over $11 \%$ [3-6]. Fullerene exhibits a typical ball-like conjugated structure with high electron affinity, which not only enables isotropic electron transfer but also helps to form favorable bulk-heterojunction (BHJ) blend film with nanoscale phase separation for charge separation $[7,8]$. Nonetheless, the nature of large bandgap absorption for fullerene acceptors and their limited tunability in optical/ electronic properties have greatly hindered their development. Besides, most of fullerene-based OSCs generally show a large voltage loss $\left(V_{\text {loss }}\right)$ of $\sim 0.8 \mathrm{eV}$ [9], thereby limiting the achievement of high efficiency. Fortunately, these challenges that have plagued this field for a long time seem to be solved due to the emergence of a small molecule non-fullerene acceptor (NFA) in 2015, termed as ITIC (Fig. 1a), which was reported by Lin et al. [10].

ITIC exhibits a typical acceptor-donor-acceptor (A-DA) type structure (Fig. 1b), wherein a large fused $\pi$-extended core, indacenodithieno[3,2- $b]$-thiophene (IDTT), is end-capped by two strong electron-withdrawing groups, 2-(3-oxo-2,3-dihydroinden-1-ylidene)malononitrile (INCN). In such rigid A-D-A dipolar structure, a strong intramolecular charge transfer (ICT) can be generated to offer a low optical bandgap with a large extinction coefficient $\left(>10^{5} \mathrm{~cm}^{-1}\right)[10]$. This structure is also beneficial to enhancing the molecular crystallinity of acceptors to realize decent electron mobilities $\left(10^{-4}-10^{-3} \mathrm{~cm}^{2} \mathrm{~V}^{-1} \mathrm{~s}^{-1}\right)$ after forming the $\mathrm{BHJ}$ blend $[10,11]$. Moreover, the incorporation of four bulky sidechains at the center of IDTT core plays a critical role in preventing the intermolecular interactions between the donor subunits, and therefore only favors the interactions between the electron-deficient end-capping subunits to

\footnotetext{
${ }^{1}$ Key Laboratory for Material Chemistry of Energy Conversion and Storage, Ministry of Education, Hubei Key Laboratory of Material Chemistry and Service Failure, School of Chemistry and Chemical Engineering, Huazhong University of Science and Technology, Wuhan 430074, China

${ }^{2}$ State Key Laboratory and Institute of Elemento-Organic Chemistry, College of Chemistry, Nankai University, Tianjin 300071, China

* Corresponding authors (emails: lizha@hust.edu.cn (Li Z); dongbing.chem@nankai.edu.cn (Zhao D))
} 


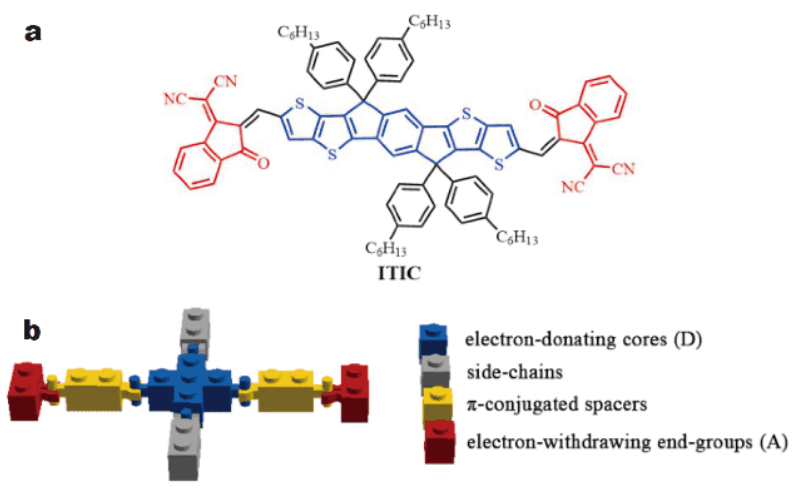

c

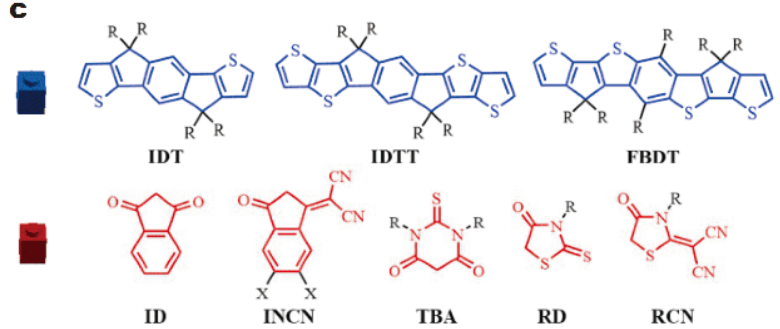

Figure 1 (a) Chemical structure of ITIC. (b) Cartoon representing a structural template for designing the A-D-A type NFAs. (c) The structures of commonly used electron-donating "D" moieties and electronwithdrawing "A" moieties.

improve the electron transport [10]. Due to these fascinating advantages, ITIC-like NFAs have made significant progress within a short time, and the derived OSCs have afforded impressive PCEs of $>15 \%$ in the single-junction devices [12-15] and $>17 \%$ in a tandem device [16], respectively, much higher than those reported in the fullerene-based OSCs.

Nowadays, more and more attentions have been paid to developing new NFAs, given the fact that their excellent synthetic flexibility can make the optical/electronic properties easily tunable to fulfill the device requirements [17]. In such A-D-A type NFAs, there are four sites that can be decorated, including electron-donating cores (D), side-chains, $\pi$-conjugated bridges/spacers and electronwithdrawing end-groups (A): (1) the regulation of " $D$ " moieties would tune the optical bandgaps, the highest occupied molecular orbital (HOMO) energy levels and the molecular crystallinity; (2) the modification of sidechains would mainly affect the solubility and the intermolecular $\pi-\pi$ stacking behaviors; (3) the introduction of $\pi$-conjugated spacers not only extends the conjugation of NFAs but also acts as a second "D" or "A" moiety to modulate the optical/electronic properties; (4) the regulation of " $\mathrm{A}$ " moieties would influence the lowest unoccupied molecular orbital (LUMO) energy levels and the electron transport of NFAs.

So far, most electron-donating "D" moieties (Fig. 1c) used for high-performance NFAs are mainly derived from the large conjugated fused-ring systems such as indacenodithiophene (IDT) [18,19], IDTT [10,20], heptacyclicbenzodi(cyclopentadithiophene) (FBDT) [21,22], etc. While in terms of electron-withdrawing " $\mathrm{A}$ " moieties, dye molecules have been often used (Fig. 1c) including 2,3-dihydro- $1 H$-indene-1,3-dione (ID) $[23,24]$, INCN [15,25-29], thiobarbituric acid (TBA) [30,31], rhodanine (RD) $[9,32], 2-(1,1$-dicyanomethylene)rhodanine (RCN) $[33,34]$, etc. Among these dyes, INCN derivatives are the most popular " $A$ " moieties toward high performance NFAs through rational structural modifications. It is worth noting that all the record PCEs reported so far, either in the single-junction devices or in the tandem devices, come from the fluorinated INCN end-capped NFAs [13,16].

In addition to INCN, RD derivatives are another type of widely used "A" moieties toward efficient NFAs. Due to the more electron-deficient property, INCN-based NFAs generally exhibit narrower bandgaps than RDbased NFAs, thereby showing higher short-circuit currents $\left(J_{\text {sc }}\right)$ beyond $20 \mathrm{~mA} \mathrm{~cm}^{-2}[35,36]$. By contrast, RDbased NFAs often present high open-circuit voltages $\left(V_{o c}\right)$ up to $1.2 \mathrm{~V}$ [37-40]. To date, the best PCE from RDbased NFAs has exceeded $12 \%$ based on a ternary-blend OSC [41]. Despite the performance of RD-based NFAs is still inferior compared with those outstanding INCNbased NFAs, an attracting feature for some RD-based NFAs is their particularly excellent compatibility with well-known poly(3-hexylthiophene) (P3HT, Scheme 1) donor, due to their well-matched energy levels and optical absorption, favorable phase-segregation film morphology with face-on dominated crystallinity, and suppressed charge recombination [42-48]. Currently, the $\mathrm{BHJ}$ blends derived from $\mathrm{P} 3 \mathrm{HT}$ donor and RD-based NFAs have produced respectable PCEs over 7\% [49], while the P3HT:ITIC blend only delivered a PCE of $1.3 \%$, which could be attributed to the strong geminate and non-geminate charge recombination caused by the almost amorphous blend film [50]. Furthermore, the structure of $\mathrm{RD}$ derivatives also can be easily modified to tune their optical/electronic properties as needed. For example, the ketone or thioketone group in the RD unit that endows the electron-withdrawing character can be further substituted by malononitrile, resulting in the RCN unit with much stronger electron-deficient ability. Also, simply altering the imide alkyl chains in the $\mathrm{RD}$ unit can regulate the materials' solubility as well as the intermolecular $\pi-\pi$ 

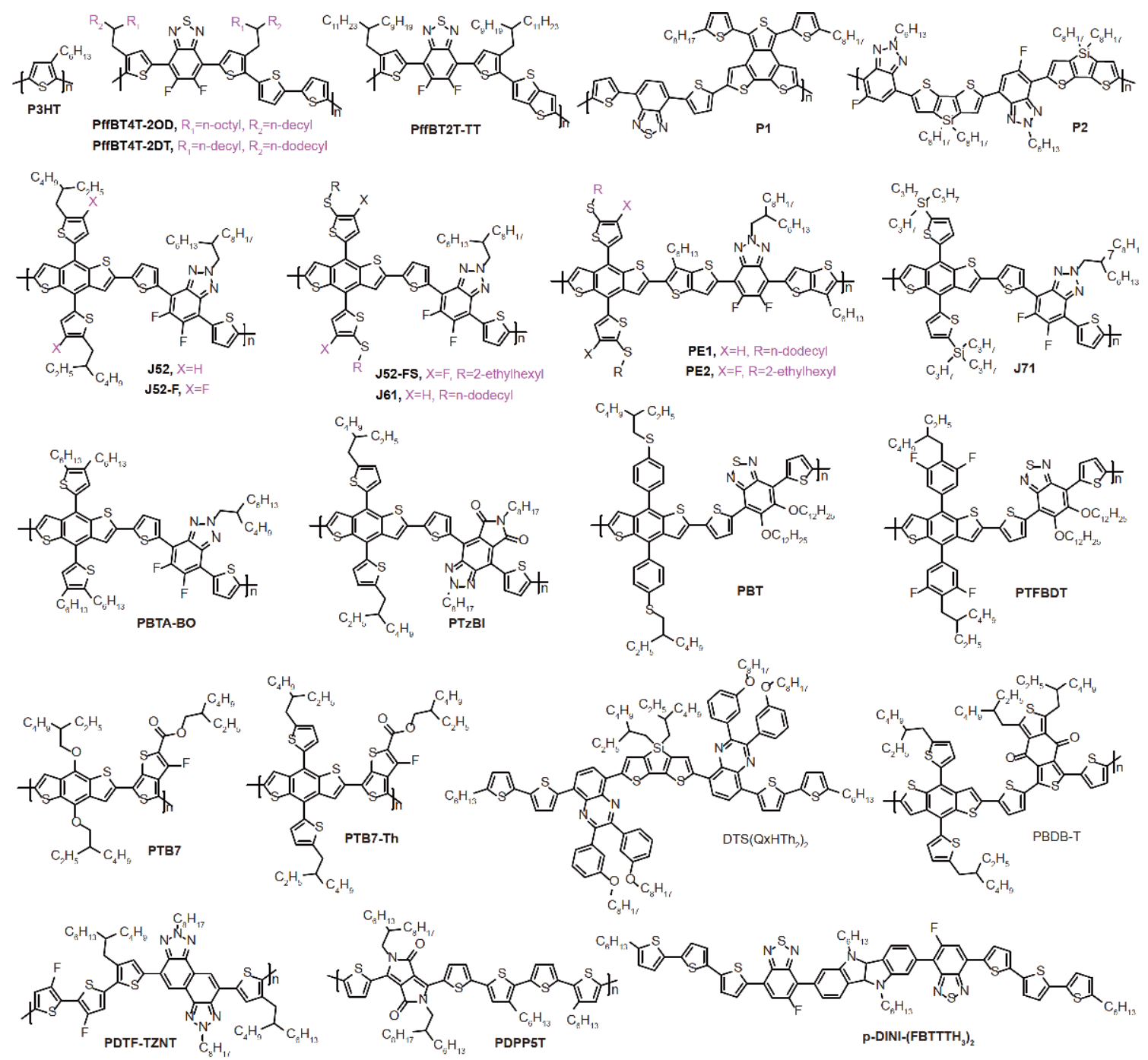

Scheme 1 A summary of donors paired with newly-developed RD-based NFAs.

stacking to optimize the blend film and thus to boost the device performance.

In 2011, Li et al. [51] first synthesized an RD-based small molecule donor material, DERHD7T, and the resulting fullerene-based OSCs delivered the highest PCE of $6.1 \%$ for small-molecule based OSCs at that time. Subsequently, more efforts have been devoted on developing RD-based small molecule donors, of which the PCEs have been yet improved to over 10\% with fullerene acceptors [52-54]. In 2014, Kim and coworkers [55] first reported two new RD-based small molecule NFAs, leading to an encouraging PCE of $3.1 \%$ with P3HT donor. Soon after, Holliday et al. [56] synthesized another new RD-based NFA, FBR, with an A-A'-D-A'-A type structure by incorporating benzothiadiazole (BT) unit as the second acceptor (A') unit, enabling an enhanced PCE of $4.1 \%$ with the same P3HT donor. Since then, RD-based NFAs have been attracted significant interest, and to date, there have been more than 50 research articles reported. Although several recent reviews covering the development of NFAs have been published [17,57-61], the target of this review will particularly focus on discussing the important advances on RD-based NFAs. The discussion will be arranged as follows: (1) A-D-A type one dimensional (1D) RD-based NFAs; (2) A-D-A type three dimensional (3D) RD-based NFAs; (3) other types of RD-based NFAs such as $A-\pi-A$ structure. Finally, a brief summary and outlook will be provided with some new perspectives for the future molecular design of RD-based NFAs. We aim to provide the readers with a better understanding of the 
structure-property relationships for those RD-based NFAs.

\section{A-D-A-TYPE 1D RD-BASED NFAs}

So far, most of efficient RD-based NFAs exhibit an A-DA type $1 \mathrm{D}$ structure. In most cases, the second electronwithdrawing units are further introduced to form an AA'-D-A'-A type structure. Such structural design can broaden and red-shift the absorption and simultaneously reduce the LUMO energy levels, making the derived NFAs more compatible with polymer donors. Moreover, the 1D ladder-type structure would facilitate the intermolecular $\pi-\pi$ stacking of resulting molecules to improve the electron transport. Various fused-ring systems such as carbazole, fluorene, IDT and IDTT have been introduced as the electron-rich core. Thus in this section, the content will be organized according to the conjugation length of those fused-core structures.

\section{NFAs with a tricyclic electron-rich core}

In 2014, Lim and coworkers [55] first synthesized two RD-based NFAs, Flu-RH and Cz-RH (Scheme 2, Table 1), by using traditional carbazole and fluorene rings as the core structure, respectively. Both NFAs showed a strong absorption in the range of 400-600 nm, indicating a wide bandgap nature. They also had similar HOMO/ LUMO energy levels, and the HOMO level of $\mathbf{C z}-\mathbf{R H}$ was slightly higher than that of Flu-RH because of the more electron-donating ability of carbazole. When paired with P3HT donor, the conventional P3HT:Flu-RH OSCs afforded an enhanced PCE (3.08\%) compared with Cz-RHbased devices $(2.56 \%)$, mainly due to the higher $J_{\text {sc }}$ value of the former. Based on this structure, Holliday et al. [56] further synthesized a new acceptor (FBR, Scheme 2, Table 1) by replacing the thiophene-bridge in the Flu-RH with an electron-withdrawing BT unit. The introduction of BT unit can effectively reduce the HOMO/LUMO energy levels of the derived FBR. Moreover, the nonplanar molecular structure of FBR can not only realize a non-anisotropic electron transport but also prevent the formation of large crystalline domains in the BHJ blend. As a result, despite leading to a reduced $V_{\mathrm{oc}}$, the P3HT: FBR blend showed an impressive PCE up to $4.11 \%$, significantly outperforming that of P3HT:PC ${ }_{60} \mathrm{BM}$ blend (3.53\%). Since then, RD-based NFAs have attracted particular interest in the field of OSCs. In 2016, Baran et al. [9] further adopted a low bandgap polymer PffBT4T-2DT (Scheme 1) as the donor to blend with FBR, and demonstrated that the synergistic effect of high mobility and low recombination efficiency can efficiently suppress the non-radiative recombination of resulting devices to achieve an extremely low $V_{\text {loss }}$ of $0.47 \mathrm{~V}$. Consequently, the as-casted PffBT4T-2DT:FBR-based OSCs delivered a high PCE of $7.8 \%$ with a large $V_{\text {oc }}$ of $1.12 \mathrm{~V}$.

Inspired by these encouraging results, rational structural modifications have been conducted on FBR subsequently. For example, by replacing the fluorene core in the FBR with carbazole moiety, Ma and coworkers [62] synthesized two new RD-based NFAs, CzC6C8 and CzC8 (Scheme 2, Table 1), with branched and linear alkyl side chains, respectively. It was demonstrated that $\mathbf{C z C 8}$ with a linear $n$-octyl chain exhibited a more closely molecular stacking and a more preferred film morphology than CzC6C8 with a branched 2-hexyldecyl chain, leading to a
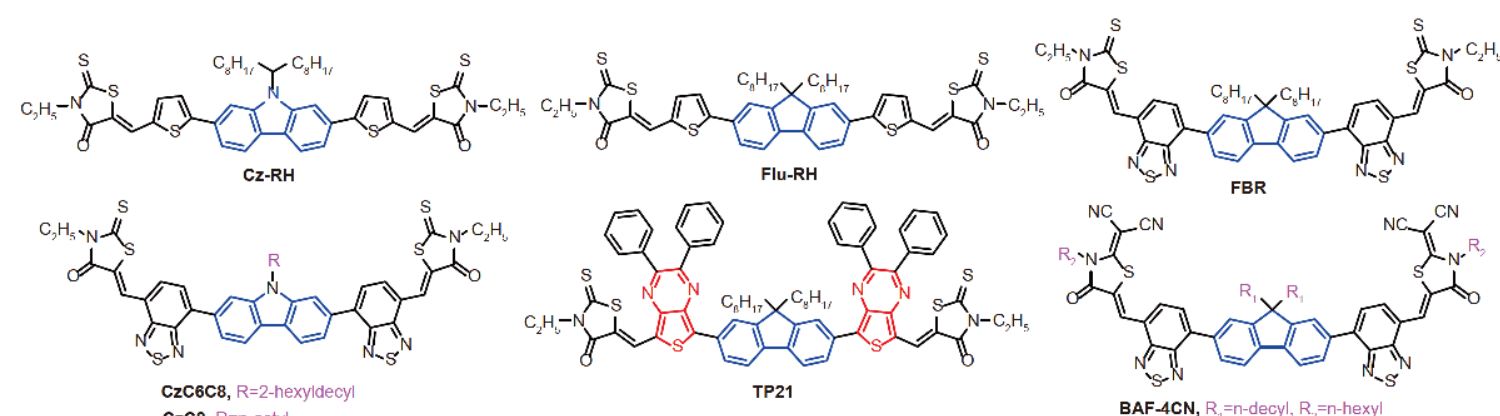

CzC8, R=n-octyl
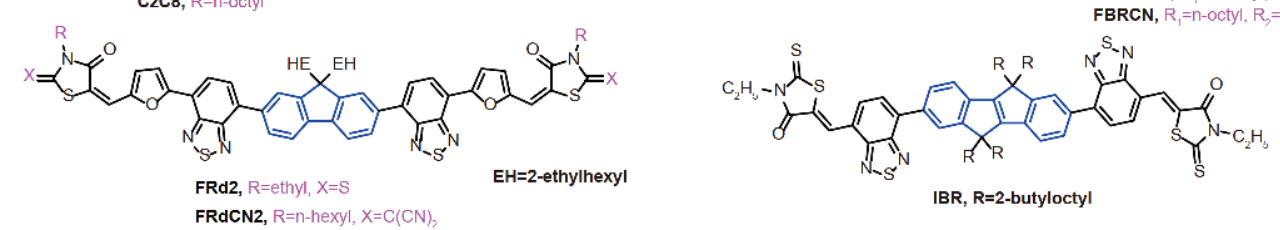

Scheme 2 Chemical structures of NFAs with a tricyclic/tetracyclic electron-rich core. 
Table 1 Summary of NFAs with a tricyclic/tetracyclic electron-rich core

\begin{tabular}{|c|c|c|c|c|c|c|c|c|c|c|c|}
\hline \multirow{2}{*}{ NFAs } & \multirow{2}{*}{$\begin{array}{c}E_{\mathrm{HOMO}} \\
(\mathrm{eV})\end{array}$} & \multirow{2}{*}{$E_{\text {LUMO }}(\mathrm{eV})$} & \multirow{2}{*}{$E_{\mathrm{g}, \mathrm{opt}}(\mathrm{eV})$} & \multirow{2}{*}{ Donor } & \multirow{2}{*}{$V_{\mathrm{oc}}(\mathrm{V})$} & \multirow{2}{*}{$\left.\left(\mathrm{mA} \mathrm{cm}^{J_{\mathrm{sc}}}\right)^{-2}\right)$} & \multirow{2}{*}{$\mathrm{FF}(\%)$} & \multirow{2}{*}{ PCE (\%) } & \multicolumn{2}{|c|}{ Mobility $\left(\mathrm{cm}^{2} \mathrm{~V}^{-1} \mathrm{~s}^{-1}\right)$} & \multirow{2}{*}{ Ref. } \\
\hline & & & & & & & & & Electron & Hole & \\
\hline $\mathrm{Cz}-\mathrm{RH}$ & $-5.53^{\mathrm{a}}$ & $-3.50^{\mathrm{a}}$ & 2.05 & P3HT & 1.03 & 4.69 & 53 & 2.56 & $3.9 \mathrm{E}-4$ & $8.0 \mathrm{E}-4$ & {$[24,55$} \\
\hline Flu-RH & $-5.58^{\mathrm{a}}$ & $-3.53^{\mathrm{a}}$ & 2.10 & P3HT & 1.03 & 5.70 & 52 & 3.08 & $4.6 \mathrm{E}-4$ & $8.5 \mathrm{E}-4$ & {$[24,55$} \\
\hline \multirow[t]{2}{*}{ FBR } & $-5.70^{\mathrm{b}}$ & $-3.57^{\mathrm{b}}$ & 2.14 & P3HT & 0.82 & 7.95 & 63 & 4.11 & $2.6 \mathrm{E}-5$ & - & {$[56]$} \\
\hline & $-5.83^{\mathrm{c}}$ & $-3.75^{\mathrm{a}}$ & 2.08 & PffBT4T-2DT & 1.12 & 11.5 & 61 & 7.8 & - & - & [9] \\
\hline $\mathrm{CzC} 6 \mathrm{C} 8$ & $-5.79^{\mathrm{a}}$ & $-3.79^{\mathrm{c}}$ & 2.00 & PBT & 0.99 & 8.24 & 41 & 3.30 & $2.9 \mathrm{E}-6$ & $1.2 \mathrm{E}-6$ & {$[62]$} \\
\hline \multirow[t]{3}{*}{$\mathrm{CzC} 8$} & $-5.72^{\mathrm{a}}$ & $-3.74^{\mathrm{c}}$ & 1.98 & PBT & 1.03 & 9.00 & 50 & 4.64 & $3.3 \mathrm{E}-6$ & $2.0 \mathrm{E}-6$ & {$[62]$} \\
\hline & $-5.72^{\mathrm{a}}$ & $-3.74^{\mathrm{c}}$ & 1.98 & PTB7-Th & 0.98 & 11.24 & 45 & 4.91 & $4.9 \mathrm{E}-5$ & $4.7 \mathrm{E}-5$ & {$[62]$} \\
\hline & $-5.72^{\mathrm{a}}$ & $-3.74^{\mathrm{c}}$ & 1.98 & PTFBDT & 1.16 & 7.99 & 51 & 4.67 & $1.6 \mathrm{E}-6$ & $1.9 \mathrm{E}-6$ & {$[62]$} \\
\hline TP21 & $-5.46^{\mathrm{a}}$ & $-3.61^{\mathrm{a}}$ & 1.65 & $\mathrm{~J} 61$ & 1.05 & 10.92 & 51 & 5.81 & $7.4 \mathrm{E}-6$ & $2.5 \mathrm{E}-4$ & [63] \\
\hline BAF-4CN & $-5.71^{b}$ & $-3.55^{\mathrm{b}}$ & 2.16 & PffBT4T-2OD & 0.77 & 15.52 & 71 & 8.40 & $4.9 \mathrm{E}-4$ & $2.9 \mathrm{E}-4$ & {$[64]$} \\
\hline FBRCN & $-5.84^{\mathrm{c}}$ & $-3.77^{\mathrm{a}}$ & 2.07 & PTB7-Th & 1.00 & 8.1 & 40 & 3.3 & $9.0 \mathrm{E}-6$ & - & [65] \\
\hline $\mathrm{FRd}_{2}$ & $-5.67^{\mathrm{b}}$ & $-3.58^{\mathrm{c}}$ & 2.09 & PTB7-Th & 0.83 & 15.7 & 72 & 9.4 & $4.3 \mathrm{E}-4$ & $2.4 \mathrm{E}-4$ & {$[66]$} \\
\hline $\mathrm{FRdCN}_{2}$ & $-5.88^{\mathrm{b}}$ & $-3.81^{\mathrm{c}}$ & 2.07 & PTB7-Th & 0.93 & 16.0 & 72 & 10.7 & $5.1 \mathrm{E}-4$ & $3.4 \mathrm{E}-4$ & {$[33]$} \\
\hline IBR & $-5.64^{\mathrm{b}}$ & $-3.41^{\mathrm{b}}$ & - & PBDB-T & 1.16 & 9.6 & 61 & 6.66 & $2.8 \mathrm{E}-4$ & $8.3 \mathrm{E}-4$ & [67] \\
\hline
\end{tabular}

a) Measured by CV based on films. b) Measured by CV in solutions. c) Calculated by $E_{\mathrm{LUMO}}=E_{\mathrm{HOMO}}+E_{\mathrm{g}, \mathrm{opt} \text {. }}$ "” indicates that the details were not reported.

better photovoltaic performance $(\mathrm{PCE}=4.91 \%)$ when paired with one of the state-of-the-art polymer donors, PTB7-Th (Scheme 1). Furthermore, Li et al. [63] synthesized another new RD-based acceptor (TP21, Scheme 2, Table 1) containing a thienopyrazine (TP) $\pi$ conjugated bridge instead of the commonly used BT unit. Compared with FBR, TP21 showed a decreased optical bandgap of $1.65 \mathrm{eV}$, but a high-lying LUMO level of $-3.61 \mathrm{eV}$, due to the highly planar and quinoid structure of TP unit that could facilitate the electron delocalization. When blended with another state-of-the-art polymer donor J61 (Scheme 1), the derived OSCs can realize a decent PCE of $5.81 \%$ with a high $V_{\text {oc }}$ of $1.05 \mathrm{~V}$.

In addition to modifying the core structure and the $\pi$ conjugated bridge, the RD end-groups in the FBR can also be replaced by the dicyano-functionalized RCN dye [64]. The obtained RCN-based acceptor, BAF-4CN (Scheme 2, Table 1), possessed similar electrochemical properties with FBR, but much stronger absorption due to the higher electron-withdrawing ability of RCN, and the molar extinction coefficient can be improved from $3.5 \times 10^{4} \mathrm{~mol}^{-1} \mathrm{~L}^{-1} \mathrm{~cm}^{-1}$ for FBR to $7.8 \times 10^{4} \mathrm{~mol}^{-1} \mathrm{~L}^{-1} \mathrm{~cm}^{-1}$ for BAF-4CN. When blended with a low bandgap polymer donor (PffBT4T-2OD, Scheme 1), a high PCE of $8.40 \%$ with a $J_{\mathrm{sc}}$ of $15.52 \mathrm{~mA} \mathrm{~cm}^{-2}$ and a fill factor (FF) of $71 \%$ was realized. Moreover, in 2018, Radford and coworkers [65] also reported an acceptor FBRCN (Scheme 2, Table 1) with a similar structure as BAF-4CN, however, containing different alkyl chains at the fluorene and RD units. When blended with the PTB7-Th donor, the FBRCN-based OSCs delivered a moderate PCE of $3.3 \%$.

Furthermore, Suman et al. [66] synthesized FRd $_{2}$ (Scheme 2, Table 1) by incorporating the furan unit as the second $\pi$-spacer between $\mathrm{RD}$ and $\mathrm{BT}$ units. The furan unit was found to extend the conjugation of the resulting $\mathbf{F R d}_{2}$ to increase the delocalization of $\pi$-electrons, leading to a much higher molar extinction coefficient $\left(7.8 \times 10^{4} \mathrm{~mol}^{-1} \mathrm{~L}^{-1} \mathrm{~cm}^{-1}\right)$ and a slightly red-shifted/broadened absorption. The derived PTB7-Th:FRd ${ }_{2}$-based OSCs demonstrated an impressive PCE of 9.4\% with a $V_{\text {oc }}$ of $0.83 \mathrm{~V}$, a $J_{\mathrm{sc}}$ of $15.7 \mathrm{~mA} \mathrm{~cm}^{-2}$ and an FF of $72 \%$. Soon after, they [33] also prepared $\mathbf{F R d C N}{ }_{2}$ (Scheme 2, Table 1) using RCN as the end-capped groups. As compared with $\mathbf{F R d}_{2}$ and BAF-4CN, FRdCN $\mathbf{C N}_{2}$ exhibited a stronger, broader and red-shifted absorption, as well as a decreased LUMO level of $-3.81 \mathrm{eV}$. With the help of 1chloronaphthalene $(\mathrm{CN})$ additive and solvent vapor annealing (SVA) treatment, the fabricated PTB7-Th: FRdCN $_{2}$ based OSCs produced an excellent PCE of $10.70 \%$ with a $V_{\text {oc }}$ of $0.93 \mathrm{~V}$, a $J_{\text {sc }}$ of $16.0 \mathrm{~mA} \mathrm{~cm}^{-2}$ and an FF of $72 \%$, among the best of the binary-blend singlejunction OSCs using RD-based NFAs.

\section{NFAs with a tetracyclic electron-rich core}

In 2019, Zulfiqar et al. [67] also developed an in- 
denoindene-cored small molecule acceptor, IBR (Scheme 2, Table 1). Compared with the fluorene-cored FBR, IBR showed an elevated HOMO energy level and a red-shifted absorption attributed to its stronger electrondonating core. Adopting PBDB-T (Scheme 1) as the donor, the as-cast PBDB-T:IBR devices only yielded a poor PCE of $0.68 \%$ with a $V_{\text {oc }}$ of $0.88 \mathrm{~V}$. While, the optimal OSCs can afford a much higher PCE of $6.66 \%$ with an improved $V_{\mathrm{oc}}$ of $1.16 \mathrm{~V}$ when annealing at $160^{\circ} \mathrm{C}$ for $10 \mathrm{~min}$. It was shown that the thermal-annealing treatment can diminish the morphological defects to reduce the bimolecular recombination and the saturation dark current density.

\section{NFAs with a pentacyclic electron-rich core}

So far, the pentacyclic IDT unit is the most studied electron-rich core for RD-based NFAs. IDT was first reported by Wong et al. [68] in 2006. The large and rigid planar conjugated structure of IDT has been demonstrated to facilitate the $\pi$-electron delocalization and the intermolecular $\pi-\pi$ interaction of the resulting molecules/ polymers to promote the charge transport [68]. Initially, IDT was mainly used to construct donor materials in
OSCs [69], and the first A-D-A type IDT-based NFAs, IDT-2DPP, was reported by Bai et al. [70] in 2013 by using diketopyrrolopyrrole (DPP) as the end-capped groups for IDT. Later on, numerous high-performance NFAs with IDT and its derivatives as the core have been designed and synthesized using RD and INCN as the endcapped groups.

In 2015, Wu et al. [42] first developed an IDT-RDbased acceptor, IDT-2BR (Scheme 3, Table 2), wherein IDT unit was introduced as the core to replace the fluorene unit of FBR. Due to the large and planar conjugated structure of IDT, IDT-2BR exhibited a lower optical bandgap (1.68 eV), a stronger optical absorption, and a higher electron mobility than FBR. Therefore, the P3HT:IDT-2BR OSCs showed a higher PCE up to 5.12\% due to the simultaneous increase of $J_{\text {sc }}$ and FF. Sequentially, they also fabricated a semitransparent all-plastic OSC based on the P3HT:IDT-2BR blend to achieve a PCE of $2.88 \%$ under an average visible transmittance of ca. 50\% [71]. Further fabricating a PTB7-Th:IDT-2BR blend, Tang and coworkers [72] reported a significantly enhanced PCE of $8.96 \%$ with a high $V_{\text {oc }}$ of $1.04 \mathrm{~V}$ and a low $E_{\text {loss }}$ of $0.55 \mathrm{eV}$, attributed to the improved solar ab-

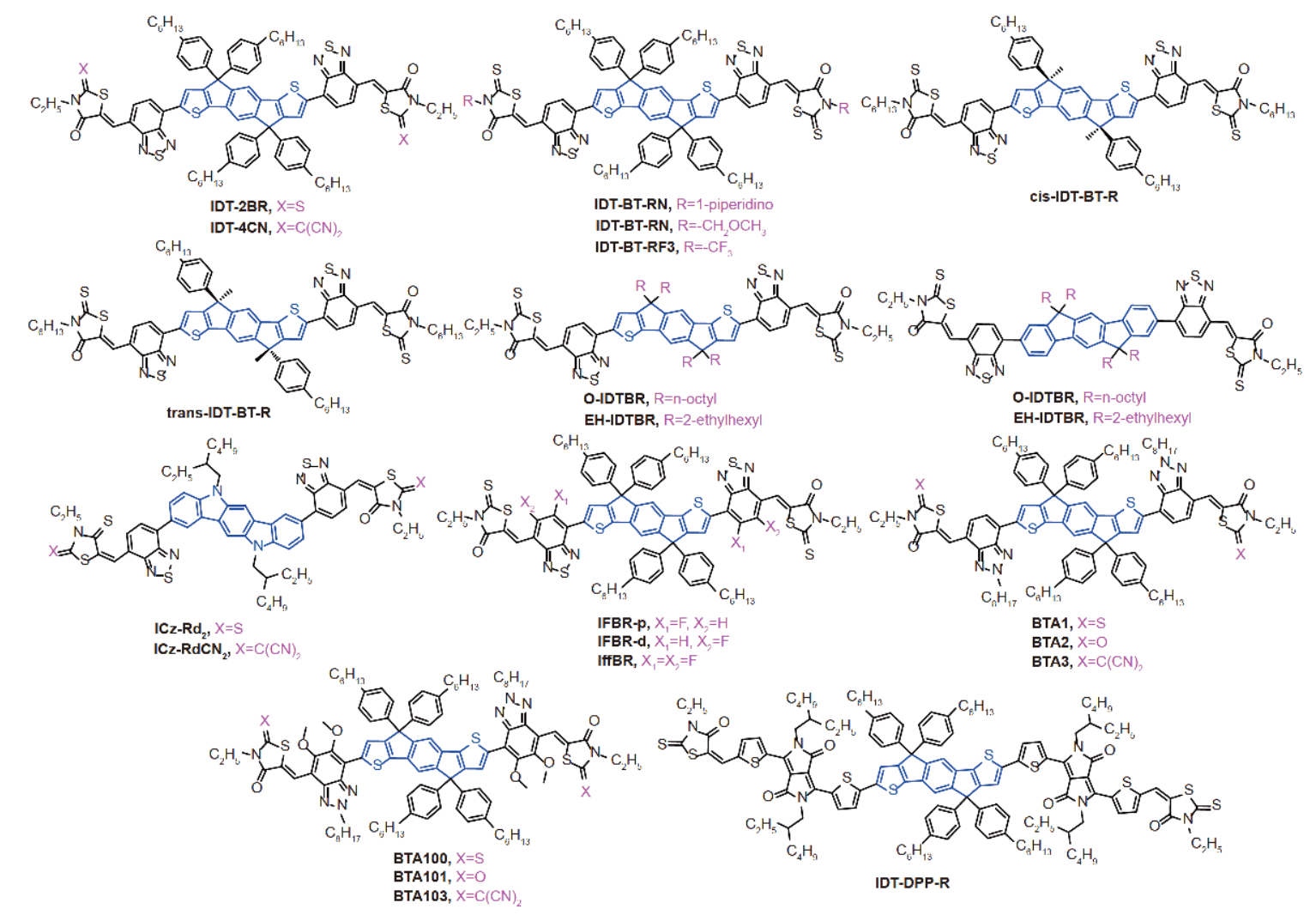

Scheme 3 Chemical structures of NFAs with a pentacyclic electron-rich core. 
Table 2 Summary of NFAs with a pentacyclic electron-rich core

\begin{tabular}{|c|c|c|c|c|c|c|c|c|c|c|c|}
\hline \multirow{2}{*}{ NFAs } & \multirow{2}{*}{$\begin{array}{c}E_{\mathrm{HOMO}} \\
(\mathrm{eV})\end{array}$} & \multirow{2}{*}{$E_{\text {LUMO }}(\mathrm{eV})$} & \multirow{2}{*}{$E_{\mathrm{g}, \mathrm{opt}}(\mathrm{eV})$} & \multirow{2}{*}{$\begin{array}{l}\text { Donor: 2nd } \\
\text { component }\end{array}$} & \multirow{2}{*}{$V_{\mathrm{oc}}(\mathrm{V})$} & \multirow{2}{*}{$\left(\mathrm{mA} \mathrm{cm}^{J_{\mathrm{sc}}}{ }^{-2}\right)$} & \multirow[t]{2}{*}{$\mathrm{FF}(\%)$} & \multirow[t]{2}{*}{ PCE (\%) } & \multicolumn{2}{|c|}{$\begin{array}{l}\text { Mobility } \\
\left(\mathrm{cm}^{2} \mathrm{~V}^{-1} \mathrm{~s}^{-1}\right)\end{array}$} & \multirow[t]{2}{*}{ Ref. } \\
\hline & & & & & & & & & Electron & Hole & \\
\hline \multirow[t]{3}{*}{ IDT-2BR } & $-5.52^{\mathrm{a}}$ & $-3.69^{\mathrm{a}}$ & 1.68 & P3HT & 0.84 & 8.91 & 68 & 5.12 & $2.6 \mathrm{E}-4$ & $2.0 \mathrm{E}-4$ & [42] \\
\hline & $-5.52^{\mathrm{a}}$ & $-3.69^{\mathrm{a}}$ & 1.68 & P3HT & 0.84 & 5.93 & 58 & 2.88 & - & - & [71] \\
\hline & $-5.31^{\mathrm{a}}$ & $-3.70^{\mathrm{a}}$ & 1.68 & PTB7-Th & 1.04 & 13.75 & 63 & 8.96 & $9.1 \mathrm{E}-5$ & $1.2 \mathrm{E}-3$ & [72] \\
\hline IDT-BT-RO & $-5.33^{\mathrm{a}}$ & $-3.74^{\mathrm{a}}$ & 1.66 & PTB7-Th & 1.02 & 13.75 & 61 & 8.57 & $9.1 \mathrm{E}-5$ & $1.3 \mathrm{E}-3$ & [72] \\
\hline IDT-BT-RF3 & $-5.35^{\mathrm{a}}$ & $-3.78^{\mathrm{a}}$ & 1.64 & PTB7-Th & 0.89 & 14.74 & 59 & 7.75 & $1.3 \mathrm{E}-4$ & $1.8 \mathrm{E}-3$ & [72] \\
\hline IDT-BT-RN & $-5.26^{\mathrm{a}}$ & $-3.62^{\mathrm{a}}$ & 1.71 & PTB7-Th & 1.10 & 12.04 & 54 & 7.09 & $8.8 \mathrm{E}-5$ & $1.4 \mathrm{E}-3$ & [72] \\
\hline cis-IDT-BTR & $-5.44^{\mathrm{a}}$ & $-3.62^{\mathrm{a}}$ & 1.64 & PTB7-Th & 1.08 & 13.79 & 58 & 8.02 & $1.0 \mathrm{E}-6$ & $5.9 \mathrm{E}-4$ & [73] \\
\hline $\begin{array}{l}\text { trans-IDT- } \\
\text { BTR }\end{array}$ & $-5.43^{\mathrm{a}}$ & $-3.61^{\mathrm{a}}$ & 1.63 & PTB7-Th & 1.05 & 15.08 & 60 & 9.43 & $2.2 \mathrm{E}-6$ & $8.9 \mathrm{E}-4$ & [73] \\
\hline \multirow[t]{4}{*}{ O-IDTBR } & $-5.51^{c}$ & $-3.88^{\mathrm{a}}$ & 1.63 & P3HT & 0.73 & 14.1 & 62 & 6.4 & - & - & [43] \\
\hline & $-5.51^{\mathrm{c}}$ & $-3.88^{\mathrm{a}}$ & 1.63 & P3HT (34 kDa) & 0.73 & 14.6 & 66 & 7.0 & - & - & [49] \\
\hline & $-5.51^{c}$ & $-3.88^{\mathrm{a}}$ & 1.63 & PffBT4T-2DT & 1.07 & 15.0 & 62 & 9.95 & - & - & [9] \\
\hline & $-5.51^{\mathrm{c}}$ & $-3.88^{\mathrm{a}}$ & 1.63 & PffBT2T-TT & 1.08 & 14.32 & 67 & 10.4 & - & - & [75] \\
\hline \multirow[t]{2}{*}{ EH-IDTBR } & $-5.58^{\mathrm{c}}$ & $-3.90^{\mathrm{a}}$ & 1.68 & P3HT & 0.77 & 12.2 & 62 & 6.05 & - & - & [43] \\
\hline & $-5.58^{\mathrm{c}}$ & $-3.90^{\mathrm{a}}$ & 1.68 & PffBT4T-2OD & 1.03 & 16.1 & 55 & 9.1 & - & - & [74] \\
\hline \multirow[t]{2}{*}{ O-IDFBR } & $-5.75^{\mathrm{a}}$ & $-3.70^{\mathrm{a}}$ & 2.0 & P3HT:O-IDTBR & 0.82 & 14.4 & 64 & 7.7 & - & - & [32] \\
\hline & $-5.75^{\mathrm{a}}$ & $-3.70^{\mathrm{a}}$ & 2.0 & $\begin{array}{l}\text { PTB7-Th: } \\
\text { O-IDTBR }\end{array}$ & 1.03 & 17.2 & 60 & 11.0 & - & - & {$[32]$} \\
\hline EH-IDFBR & $-5.75^{\mathrm{c}}$ & $-3.70^{\mathrm{a}}$ & & PffBT4T-2DT & 1.08 & 4.4 & 38 & 1.75 & - & - & [9] \\
\hline IDT-4CN & $-5.45^{\mathrm{c}}$ & $-3.95^{\mathrm{b}}$ & 1.50 & PBDB-T & 0.91 & 14.66 & 61 & 8.13 & $1.9 \mathrm{E}-4$ & $3.5 \mathrm{E}-4$ & [76] \\
\hline $\begin{array}{l}\text { IDT-BT- } \\
\text { R-CN }\end{array}$ & $-5.38^{\mathrm{a}}$ & $-3.67^{\mathrm{a}}$ & 1.63 & PTB7-Th & 0.88 & 12.4 & 50 & 5.7 & $8.7 \mathrm{E}-4$ & $1.3 \mathrm{E}-3$ & [77] \\
\hline $\mathrm{ICz}-\mathrm{Rd}_{2}$ & $-5.59^{\mathrm{b}}$ & $-3.88^{\mathrm{c}}$ & 1.71 & P1 & 1.04 & 14.04 & 54 & 7.88 & - & - & [78] \\
\hline ICz-RdCN 2 & $-5.58^{\mathrm{b}}$ & $-3.98^{\mathrm{c}}$ & 1.61 & P1 & 1.01 & 15.58 & 62 & 9.76 & - & - & [78] \\
\hline IFBR- $p$ & $-5.64^{\mathrm{a}}$ & $-3.73^{\mathrm{a}}$ & 1.67 & PTzBI & 1.00 & 11.6 & 62 & 7.44 & $1.5 \mathrm{E}-4$ & $5.8 \mathrm{E}-5$ & [79] \\
\hline IFBR- $d$ & $-5.67^{\mathrm{a}}$ & $-3.74^{\mathrm{a}}$ & 1.71 & PTzBI & 0.99 & 9.4 & 56 & 5.28 & $4.9 \mathrm{E}-5$ & $5.9 \mathrm{E}-5$ & [79] \\
\hline \multirow[t]{2}{*}{ IffBR } & $-5.71^{\mathrm{a}}$ & $-3.77^{\mathrm{a}}$ & 1.71 & PBTA-BO & 1.013 & 11.77 & 52 & 6.34 & - & - & [80] \\
\hline & $-5.71^{\mathrm{a}}$ & $-3.77^{\mathrm{a}}$ & 1.71 & $\begin{array}{l}\text { PBTA-BO: } \\
\text { PC }_{71} \mathrm{BM}\end{array}$ & 0.91 & 14.52 & 67 & 9.06 & - & - & [80] \\
\hline BTA1 & $-5.46^{\mathrm{a}}$ & $-3.57^{\mathrm{a}}$ & 1.87 & $\mathrm{~J} 61$ & 1.24 & 5.21 & 47 & 3.02 & $5.4 \mathrm{E}-5$ & $1.9 \mathrm{E}-4$ & [38] \\
\hline BTA2 & $-5.43^{\mathrm{a}}$ & $-3.46^{\mathrm{a}}$ & 2.00 & J61 & 1.29 & 0.84 & 24 & 0.26 & $2.4 \mathrm{E}-5$ & $9.8 \mathrm{E}-5$ & [38] \\
\hline \multirow[t]{5}{*}{ BTA3 } & $-5.49^{\mathrm{a}}$ & $-3.61^{\mathrm{a}}$ & 1.76 & J61 & 1.15 & 10.84 & 66 & 8.25 & $2.2 \mathrm{E}-4$ & $3.3 \mathrm{E}-4$ & [38] \\
\hline & $-5.49^{\mathrm{a}}$ & $-3.61^{\mathrm{a}}$ & 1.76 & PE1 & 1.11 & 11.95 & 64 & 8.43 & $4.5 \mathrm{E}-6$ & $2.2 \mathrm{E}-4$ & [81] \\
\hline & $-5.49^{\mathrm{a}}$ & $-3.61^{\mathrm{a}}$ & 1.76 & PE2 & 1.26 & 8.06 & 57 & 5.83 & $2.4 \mathrm{E}-6$ & $5.5 \mathrm{E}-5$ & [81] \\
\hline & $-5.49^{\mathrm{a}}$ & $-3.61^{\mathrm{a}}$ & 1.76 & $\mathrm{~J} 71$ & 1.20 & 10.39 & 69 & 8.60 & $8.3 \mathrm{E}-4$ & $4.9 \mathrm{E}-4$ & [40] \\
\hline & $-5.49^{\mathrm{a}}$ & $-3.61^{\mathrm{a}}$ & 1.76 & P3HT & 0.90 & 9.64 & 65 & 5.64 & $1.8 \mathrm{E}-4$ & $1.6 \mathrm{E}-6$ & [46] \\
\hline BTA100 & $-5.32^{\mathrm{a}}$ & $-3.23^{\mathrm{a}}$ & 2.05 & P3HT & 1.34 & 1.65 & 47 & 1.04 & $6.9 \mathrm{E}-9$ & $4.4 \mathrm{E}-8$ & [39] \\
\hline BTA101 & $-5.41^{\mathrm{a}}$ & $-3.55^{\mathrm{a}}$ & 1.88 & Р3HT & 1.19 & 5.33 & 56 & 3.55 & $1.4 \mathrm{E}-7$ & $2.3 \mathrm{E}-7$ & [39] \\
\hline BTA103 & $-5.37^{\mathrm{a}}$ & $-3.64^{\mathrm{a}}$ & 1.77 & P3HT & 0.94 & 8.56 & 66 & 5.31 & $3.5 \mathrm{E}-5$ & $1.5 \mathrm{E}-6$ & [39] \\
\hline \multirow[t]{2}{*}{ IDT-DPP-R } & $-5.39^{\mathrm{a}}$ & $-3.55^{\mathrm{a}}$ & 1.44 & P3HT & 0.65 & 4.07 & 54 & 1.46 & - & - & [82] \\
\hline & $-5.39^{\mathrm{a}}$ & $-3.55^{\mathrm{a}}$ & 1.44 & P3HT:PC ${ }_{61} \mathrm{BM}$ & 0.62 & 9.47 & 65 & 3.95 & - & - & [82] \\
\hline
\end{tabular}

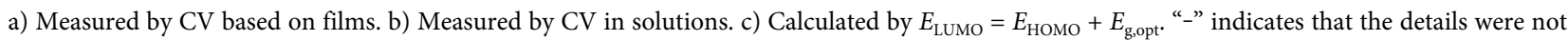
reported. 
sorption and electron transport. In addition, they also prepared another three NFAs, IDT-BT-RN, IDT-BT-RO, and IDT-BT-RF3 (Scheme 3, Table 2), by inserting 1-piperidino, methoxymethyl and trifluoroethyl groups into the end-capped RD units, respectively. Compared with the ethyl group, 1-piperidino group can reduce the electron-withdrawing ability of RD units to induce a blueshifted absorption and an elevated LUMO level for IDTBT-RN due to its electron-donating property. Thus, the PTB7-Th:IDT-BT-RN OSCs displayed a higher $V_{\text {oc }}$ of $1.10 \mathrm{~V}$ with a lower $E_{\text {loss }}$ of $0.49 \mathrm{eV}$. By contrast, the methoxymethyl and trifluoroethyl groups were found to red-shift the absorption and reduce the LUMO levels of the corresponding NFAs. As a result, both PTB7-Th:IDTBT-RO and PTB7-Th:IDT-BT-RF3 based OSCs showed more efficient charge separation and less monomolecular recombination to enable much higher $J_{\mathrm{sc}}$ than that of PTB7-Th:IDT-2BR based devices.

Side-chain engineering has been shown as an effective approach to modulate the intermolecular interactions of organic semiconductors. Cao et al. [73] reported two new stereoisomers with asymmetrical side chains, namely cisIDT-BT-R and trans-IDT-BT-R (Scheme 3, Table 2). Different side-chain configurations negligibly affected the photo-physical and electrochemical properties of the two stereoisomers, however, showed a significant impact on the crystallinity and packing behaviors. Due to the enhanced crystallinity of the centrosymmetric trans-IDTBT-R, the derived OSCs based on PTB7-Th donor demonstrated much better charge transport properties to afford a higher PCE of $9.43 \%$ than that of PTB7-Th:cisIDT-BT-R blend.

Moreover, Holliday et al. [43] also reported another two IDT-RD-based NFAs, O-IDTBR and EH-IDTBR (Scheme 3, Table 2), by replacing the bulky 4-hexylphenyl side chains in the IDT-2BR with different alkyl side chains. It was found that the alkyl chain substitutions could enable significantly red-shifted absorption in the film state due to the presence of strong intermolecular interactions. Furthermore, the increased crystallinity was found to be beneficial to charge separation/extraction. In detail, O-IDTBR with linear $n$-octyl chains was more crystalline and thus displayed a more red-shifted absorption band relative to EH-IDTBR with branched 2ethylhexyl chains, resulting in a higher $J_{\mathrm{sc}}$ and PCE (6.4\%) with the P3HT donor. More encouragingly, when paired with a $34 \mathrm{kDa}$ P3HT donor, the derived O-IDTBR-based OSC can deliver an exceptional PCE over $7.0 \%$ due to the optimal BHJ film morphology with suitable donor and acceptor domains [49]. On the other hand, Zhang et al.
[74] fabricated an inverted PffBT4T-2OD:EH-IDTBR device, which could maintain a high PCE of $9.1 \%$ even with an active layer thickness of $300 \mathrm{~nm}$. In this work, they found that the inverted device architecture could overcome the space-charge effects by shortening the transport distance of electrons for efficient charge collection, efficiently reducing the accumulation of electrons at interface in comparison with the conventional device architecture.

Afterwards, Baran et al. [32] further developed an indeno[1,2-b]fluorene-cored acceptor, O-IDFBR (Scheme 3, Table 2), showing slightly raised HOMO/ LUMO energy levels but similar absorption properties compared with FBR. By using O-IDFBR as the third component, the derived P3HT:O-IDTBR:O-IDFBR ternary OSCs offered a very encouraging PCE of 7.8\% without any solvent additives [32]. This high device performance could be attributed to the positive microstructure changes induced by adding O-IDFBR as the third component, which could reduce the charge recombination and improve light-harvesting ability across the visible region effectively. More encouragingly, they further found that the storage lifetime and photo-stability of the derived ternary devices can be significantly improved in ambient conditions in comparison with highefficiency polymer:fullerene solar cells (Fig. 2). Furthermore, they also fabricated the ternary cells by pairing the low-bandgap polymer PTB7-Th with O-IDTBR and OIDFBR, and the resulting devices produced a PCE as high as $11.4 \%$, which was almost comparable to those from INCN-based NFAs.

Later on, a low bandgap polymer PffBT4T-2DT (Scheme 1) was also used to pair with O-IDTBR [9], and the fabricated OSCs also delivered an encouraging PCE up to $10 \%$ with a high $V_{\text {oc }}$ of $1.07 \mathrm{~V}$. It is worth noting that a remarkably high $\mathrm{EQE}$ value of $75 \%$ was achieved in this device. Nonetheless, when blending PffBT4T-2DT with EH-IDFBR (Scheme 3, Table 2), the resulting OSCs only showed a poor PCE of $1.75 \%$ due to the significant decrease of both $J_{\mathrm{sc}}$ and FF. In addition, Chen and coworkers [75] designed and synthesized a new polymer donor, PffBT2T-TT (Scheme 1), with identical bandgaps and energy levels with those of O-IDTBR. An impressive PCE of $10.4 \%$ was realized with a small $V_{\text {loss }}$ of $0.55 \mathrm{~V}$, although the charge driving forces between donor and acceptor were very small.

Yang and coworkers [76] further synthesized an RCNbased acceptor IDT-4CN (Scheme 3, Table 2) with deeper $\mathrm{HOMO} / \mathrm{LUMO}$ energy levels and a smaller optical bandgap of $1.50 \mathrm{eV}$ in comparison with IDT-2BR. Con- 

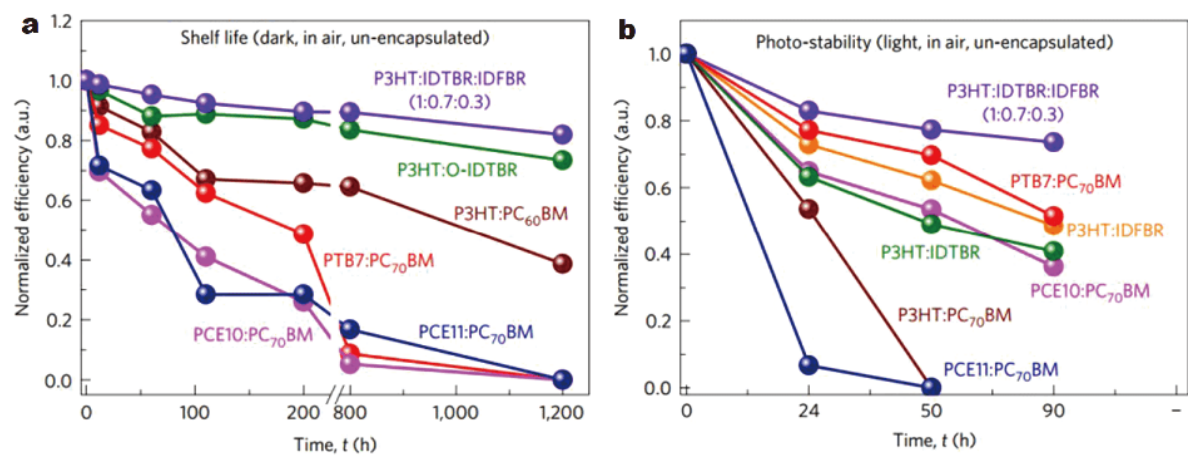

Figure 2 Storage lifetime and photo-stability of P3HT:O-IDTBR:O-IDFBR and high-efficiency, low-bandgap polymer:fullerene devices. (a) Shelf storage lifetime (dark, in air) comparison of P3HT:O-IDTBR:O-IDFBR device efficiencies with other polymer:fullerene systems. Devices were exposed to ambient conditions over a $1200 \mathrm{~h}$ duration or until high devices no longer showed any diode behaviour. (b) Photo-stability of P3HT:OIDTBR:O-IDFBR device and polymer:fullerene solar cells (in air, un-encapsulated, under AM1.5 illumination at 1 sun) for $90 \mathrm{~h}$. Reprinted with permission from Ref. [32]. Copyright 2017, Nature Publishing Group.

sequently, the IDT-4CN-based OSCs afforded a higher PCE of $8.13 \%$ with the medium bandgap polymer donor PBDB-T. Moreover, we have to note that the hexyl analogue IDT-BT-R-CN (Scheme 3, Table 2) yielded an inferior PCE of 5.3\% when blended with PTB7-Th [77].

Two new indolo[3,2-b]carbazole (ICz) cored NFAs $\left(\mathbf{I C z}-\mathbf{R d}_{\mathbf{2}}\right.$ and ICz-RdCN $\mathbf{C}_{\mathbf{2}}$, Scheme 3 and Table 2) recently were reported by Suman et al. [78]. The more electron-rich ICz core can result in a more efficient ICT, and thus both molecules showed decreased LUMO levels compared with $\mathbf{C z C 6 C 8}$. In particular, ICz- $\mathbf{R d C N}_{2}$ had a much lower LUMO level of $-3.98 \mathrm{eV}$ than ICz-Rd $\mathbf{R}_{2}$ due to the use of more electron-deficient RCN end-groups. Moreover, both new NFAs showed a strong aggregation in the film state, and particularly for $\mathbf{I C z}-\mathbf{R d C N}$, a redshifted absorption up to $60 \mathrm{~nm}$ can be observed. With a low bandgap polymer donor P1 (Scheme 1), both ICz$\mathbf{R d}_{\mathbf{2}}$ and ICz-RdCN $\mathbf{~}_{\mathbf{2}}$ can enable high-performance OSCs with high PCEs of $7.88 \%$ and $9.76 \%$, respectively, outperforming that of the reference $\mathrm{PC}_{71} \mathrm{BM}$-based one (5.89\%).

Based on the IDT-2BR acceptor, Zhong et al. [79] studied the effect of fluorination on the BT unit, and synthesized two regioregular NFAs, IFBR-p and IFBR- $\boldsymbol{d}$ (Scheme 3, Table 2), wherein the orientation of monofluorine substitution on the BT unit was controlled with respect to the IDT core. In spite of having similar optical and electrochemical properties in solutions, the simulated conformational diversity and the electrostatic potential of these two acceptors were quite different with each other. When blended with a wide bandgap polymer donor (PTzBI, Scheme 1), the derived IFBR-d-based BHJ blend showed a more pronounced crystallization and a larger scale phase separation than the IFBR-p-based blend. As a result, the PTzBI:IFBR- $\boldsymbol{p}$ based OSCs delivered an enhanced PCE of 7.44\%.

Meanwhile, the tetrafluorinated IffBR (Scheme 3, Table 2) was also synthesized by Zhong et al. [80], with significantly decreased energy levels in comparison with IDT-2BR. IffBR presented a maximum absorption at $658 \mathrm{~nm}$ with an optical bandgap of $1.71 \mathrm{eV}$. With the polymer donor PBTA-BO (Scheme 1), a higher PCE of $6.24 \%$ was yielded in comparison with that of IDT-2BRbased control device. Furthermore, through introducing $\mathrm{PC}_{71} \mathrm{BM}$ as the third component, the photovoltaic performance of the resulting ternary device (PBTA-BO: $\mathrm{PC}_{71} \mathrm{BM}$ :IffBR) can be further boosted to enable a PCE up to $9.06 \%$, attributed to the broadened absorption, the formation of cascade charge-transfer pathways, the reduced nongeminate recombination and the more favorable BHJ morphology.

On the other hand, benzotriazole (BTA) unit has been also successfully used as the second A' moiety for efficient IDT-RD-based NFAs. The additional $\mathrm{N}$ atom in the BTA unit can make it more electron-rich than the BT counterpart. In 2018, Tang et al. [38] designed and synthesized three IDT-BTA-RD-based NFAs (BTA1-3, Scheme 3, Table 2) with different substitutions on the 2-position of $\mathrm{RD}$ moiety, including oxygen atom, sulfur atom and dicyanomethylene group, respectively. As the electron deficiency of end-groups increases from BTA2, to BTA1 and to BTA3, the resulting NFAs gradually exhibit decreased HOMO/LUMO energy levels and red-shifted absorption. In this material system, the J61:BTA3 devices show a satisfied PCE of $8.25 \%$ with a high $V_{\text {oc }}$ of $1.15 \mathrm{~V}$, one of the highest $V_{\text {oc }}$ reported at that time (Fig. 3), due 


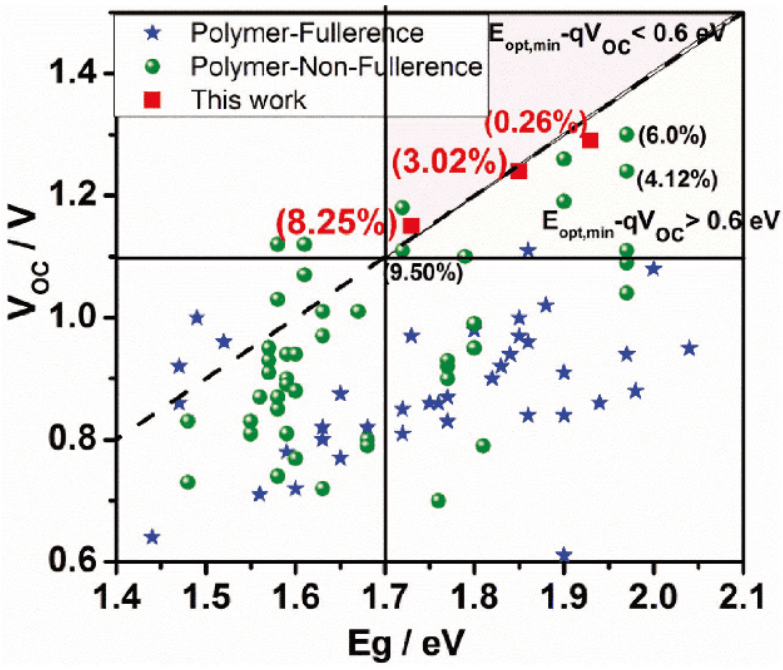

Figure 3 Plot of $V_{\mathrm{oc}}$ against $E_{\mathrm{opt} \text { min }}$ in OSCs with high PCE reported until December 2017. Reprinted with permission from Ref. [38]. Copyright 2018, Wiley-VCH.

to the matched energy levels between donor and acceptor that can provide sufficient driving force for charge separation.

In order to improve the device performance of BTA3, different paired polymer donors, like PE1, PE2, J71 and P3HT (Scheme 1), were also investigated. Replacing the thiophene $\pi$-bridge of $\mathrm{J} 61$ with thieno[3,2-b]thiophene (TT) unit can endow the derived PE1 with extended conjugation and more pronounced intermolecular $\pi-\pi$ stacking [81]. Further, PE2 with a downshifted HOMO energy level of $-5.41 \mathrm{eV}$ was also obtained by introducing fluorine atoms into the thiophene side-chains in PE1 [81]. Both OSCs fabricated from PE1 and PE2 exhibited a high $V_{\text {oc }}$ over $1.1 \mathrm{~V}$ and the PE1:BTA3 blend delivered a higher PCE of 8.43\% than PE2:BTA3 (5.83\%). However, when blended with another high-performance polymer donor J71 with trimethyl(thiophen-2-yl)silane sidechains, the PCE of derived BTA3-based OSCs can be further improved to $8.60 \%$ with a $V_{\text {oc }}$ as high as $1.2 \mathrm{~V}$ [40]. Besides, Xiao et al. [46] also fabricated the P3HT: BTA3 based OSCs, and found that a continuous pathway for electron transport can be resulted for BTA3 to further strengthen the electron mobility when forming $\mathrm{BHJ}$ blend with P3HT, thereby affording an encouraging PCE of $5.64 \%$ with a $V_{\text {oc }}$ of $0.90 \mathrm{~V}$ and an $\mathrm{FF}$ of $65 \%$, much higher than the control P3HT:IDT-4CN devices (PCE = $2.55 \%)$. These above results therefore strongly indicate that BTA is a promising building block toward highperformance RD-based NFAs.

To further study the effects of BTA unit on the RD- based NFAs, Zhang et al. [39] also synthesized BTA100, BTA101 and BTA103 (Scheme 3, Table 2). It was found that the introduction of electron-donating methoxy groups on BTA units could up-shift the LUMO energy levels of the derived NFAs to provide a possibility of improving the $V_{\mathrm{oc}}$ for P3HT-based OSCs. In this work, the RCN-based acceptor BTA103 showed the best photovoltaic performance with P3HT donor, with a PCE of $5.31 \%$ and a $V_{\text {oc }}$ of $0.94 \mathrm{~V}$. Note that despite BTA100 had a very poor PCE of $1.04 \%$, the resulting $V_{\text {oc }}$ of $1.34 \mathrm{~V}$ could be one of the highest values for P3HT-based solar cells reported thus far.

Additionally, DPP unit has been also introduced as the second A' moiety between IDT and RD units, affording a new acceptor, IDT-DPP-R (Scheme 3, Table 2) [82]. Since DPP is more electron-deficient than both BT and BTA units, the resulting HOMO/LUMO energy levels as well as absorption band of IDT-DPP-R were significantly reduced. Nonetheless, the fabricated P3HT:IDT-DPP-R OSCs only delivered a PCE of $1.42 \%$. Fortunately, when used as the third component in the ternary devices, IDTDPP-R not only extended the active layer absorption to near infrared ray (NIR) region to improve the $J_{\mathrm{sc}}$, but also increased the $V_{\text {oc }}$ due to its higher LUMO energy level relative to $\mathrm{PC}_{61} \mathrm{BM}$. Finally, the derived ternary devices with $20 \%$ content of IDT-DPP-R yielded an average PCE of $3.84 \%$, outperforming the binary $\mathrm{P} 3 \mathrm{HT}: \mathrm{PC}_{61} \mathrm{BM}$ devices $(3.30 \%)$.

In addition to incorporating the second $\mathrm{A}^{\prime}$ moiety between IDT core and RD/RCN units, thiophene derivatives have been used as the $\pi$-conjugated bridge to tune the optical and electronic properties of the resulting NFAs. For example, Jiang and coworkers [41] synthesized a new acceptor, ITCN (Scheme 4, Table 3), wherein 2-hexylthienyl substituted IDT-core was linked with two hexyl-substituted RCN units via a 3-(2-ethylhexyl)thiophene bridge. Compared with IDT-4CN, ITCN had a higher-lying LUMO energy level and a blue-shifted absorption due to the electron-donating property of thiophene bridges. However, the thiophene bridges in the ITCN can effectively reduce its molecular planarity to prevent aggregation and phase separation in the $\mathrm{BHJ}$ blend. Therefore, although the binary PBDB-T:ITCNbased OSCs only afforded a low PCE of $2.21 \%$, the ternary OSCs can achieve an impressive PCE of $12.16 \%$ with a $V_{\text {oc }}$ of $0.95 \mathrm{~V}$ using ITCN as the third component. It was shown that in the ternary blend of PBDB-T:IT-M: ITCN, ITCN not only provided a complementary optical absorption, but also enabled a more effective exciton diffusion. 


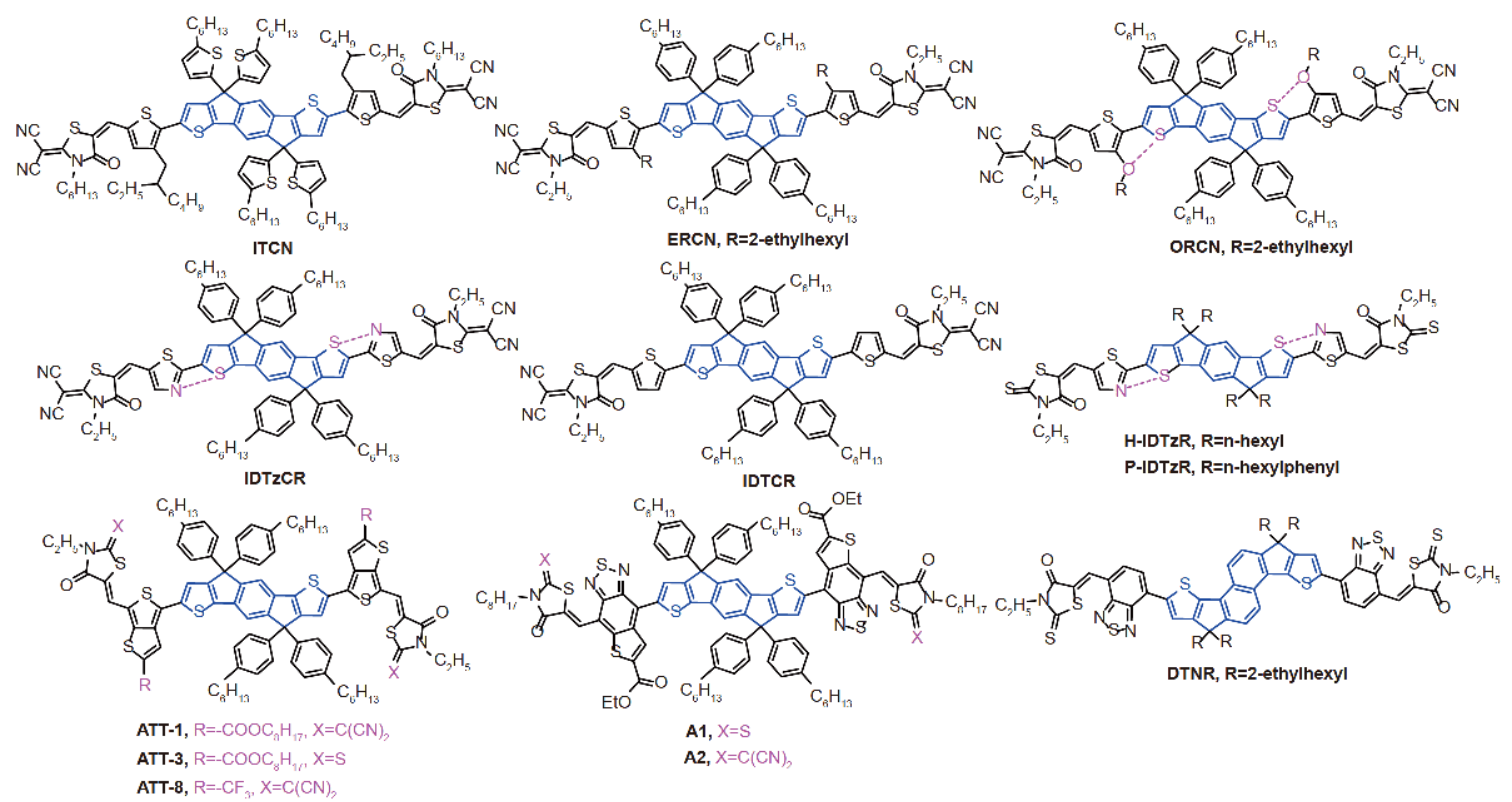

Scheme 4 Chemical structures of NFAs with a pentacyclic/hexacyclic electron-rich core.

Table 3 Summary of NFAs with a pentacyclic/hexacyclic electron-rich core

\begin{tabular}{|c|c|c|c|c|c|c|c|c|c|c|c|}
\hline \multirow{2}{*}{ Acceptor } & \multirow{2}{*}{$\begin{array}{c}E_{\mathrm{HOMO}} \\
(\mathrm{eV})\end{array}$} & \multirow{2}{*}{$E_{\text {LUMO }}(\mathrm{eV})$} & \multirow{2}{*}{$E_{\mathrm{g}, \mathrm{ppt}}(\mathrm{eV})$} & \multirow{2}{*}{ Donor } & \multirow{2}{*}{$V_{\mathrm{oc}}(\mathrm{V})$} & \multirow{2}{*}{$\begin{array}{c}J_{\mathrm{sc}} \\
\left(\mathrm{mA} \mathrm{cm}^{-2}\right)\end{array}$} & \multirow{2}{*}{$\mathrm{FF}(\%)$} & \multirow{2}{*}{ PCE (\%) } & \multicolumn{2}{|c|}{ Mobility $\left(\mathrm{cm}^{2} \mathrm{~V}^{-1} \mathrm{~s}^{-1}\right)$} & \multirow{2}{*}{ Ref. } \\
\hline & & & & & & & & & Electron & Hole & \\
\hline \multirow[t]{2}{*}{ ITCN } & $-5.40^{\mathrm{a}}$ & $-3.62^{\mathrm{a}}$ & - & PBDB-T & 1.17 & 4.97 & 37 & 2.21 & - & - & {$[41$} \\
\hline & $-5.40^{\mathrm{a}}$ & $-3.62^{\mathrm{a}}$ & - & $\begin{array}{c}\text { PBDBT: } \\
\text { IT-M }\end{array}$ & 0.95 & 17.67 & 71 & 12.16 & - & - & {$[41]$} \\
\hline ORCN & $-5.37^{\mathrm{a}}$ & $-3.56^{\mathrm{a}}$ & 1.64 & P3HT & 0.87 & 11.50 & 62 & 6.55 & $1.8 \mathrm{E}-4$ & $1.0 \mathrm{E}-4$ & {$[45$} \\
\hline ERCN & $-5.50^{\mathrm{a}}$ & $-3.59^{\mathrm{a}}$ & 1.82 & Р3HT & 0.90 & 5.87 & 50 & 2.77 & $2.7 \mathrm{E}-5$ & $2.3 \mathrm{E}-4$ & {$[45$} \\
\hline IDTzCR & $-5.67^{\mathrm{a}}$ & $-3.77^{\mathrm{a}}$ & 1.79 & PTB7-Th & 1.04 & 13.80 & 61 & 8.71 & $1.6 \mathrm{E}-5$ & $3.1 \mathrm{E}-4$ & {$[83$} \\
\hline IDTCR & $-5.46^{\mathrm{a}}$ & $-3.67^{\mathrm{a}}$ & 1.76 & PTB7-Th & 1.11 & 11.01 & 50 & 6.10 & $5.9 \mathrm{E}-6$ & $5.6 \mathrm{E}-4$ & {$[83$} \\
\hline H-IDTzR & $-5.31^{\mathrm{c}}$ & $-3.44^{\mathrm{a}}$ & 1.87 & P3HT & 1.04 & 6.67 & 53 & 3.53 & $1.8 \mathrm{E}-6$ & $1.0 \mathrm{E}-4$ & {$[48$} \\
\hline P-IDTzR & $-5.31^{\mathrm{c}}$ & $-3.42^{\mathrm{a}}$ & 1.89 & P3HT & 1.02 & 9.00 & 55 & 5.01 & $7.1 \mathrm{E}-6$ & $9.0 \mathrm{E}-5$ & {$[48$} \\
\hline ATT-1 & $-5.50^{\mathrm{b}}$ & $-3.63^{b}$ & 1.54 & PTB7-Th & 0.87 & 16.48 & 70 & 10.07 & $2.4 \mathrm{E}-4$ & $5.1 \mathrm{E}-4$ & {$[35$} \\
\hline ATT-3 & $-5.32^{\mathrm{b}}$ & $-3.40^{\mathrm{b}}$ & 1.61 & P3HT & 0.93 & 10.81 & 59 & 5.89 & $5.1 \mathrm{E}-7$ & $1.0 \mathrm{E}-5$ & {$[44$} \\
\hline ATT-8 & $-5.46^{\mathrm{a}}$ & $-3.71^{\mathrm{a}}$ & 1.55 & PBDB-T & 0.80 & 13.90 & 65 & 7.31 & $1.9 \mathrm{E}-5$ & $2.6 \mathrm{E}-4$ & {$[86$} \\
\hline A1 & $-5.66^{\mathrm{a}}$ & $-3.70^{\mathrm{a}}$ & 1.40 & PTB7-Th & 0.89 & 12.54 & 52 & 5.79 & $6.3 \mathrm{E}-5$ & $6.1 \mathrm{E}-4$ & {$[87$} \\
\hline A2 & $-5.70^{\mathrm{a}}$ & $-3.78^{\mathrm{a}}$ & 1.36 & PTB7-Th & 0.71 & 20.33 & 63 & 9.07 & $2.3 \mathrm{E}-4$ & $1.0 \mathrm{E}-3$ & {$[87$} \\
\hline DTNR & $-5.67^{\mathrm{a}}$ & $-3.75^{\mathrm{a}}$ & 1.72 & PTB7-Th & 1.08 & 15.72 & 56 & 9.51 & $2.5 \mathrm{E}-5$ & $1.8 \mathrm{E}-5$ & {$[88$} \\
\hline
\end{tabular}

a) Measured by CV based on films. b) Measured by CV in solutions. c) Calculated by $E_{\mathrm{LUMO}}=E_{\mathrm{HOмо}}+E_{\text {g,opt. }}$ "” indicates that the details were not reported.

Later on, $\mathrm{Wu}$ and coworkers [45] synthesized two thiophene-bridged NFAs, ERCN and ORCN (Scheme 4, Table 3), to study the effect of different types of alkyl chains in the thiophene bridges. In comparison with ERCN, the introduction of alkoxy chain in the ORCN was shown to enable strong $S \cdots O$ noncovalent conformational locks (NCLs) that can efficiently increase the planarity and rigidity of the backbone (Fig. 4c). Therefore, ORCN showed a significantly red-shifted absorption in the film state (Fig. 4a) due to the aggregation effect and increased HOMO/LUMO energy levels (Fig. 4b) compared with ERCN. Furthermore, such noncovalent interactions could optimize the $\mathrm{BHJ}$ film morphology to improve the charge transport mobility in the $\mathrm{BHJ}$ blend. 
a

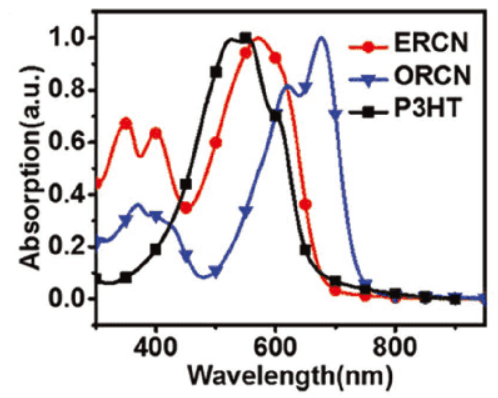

b

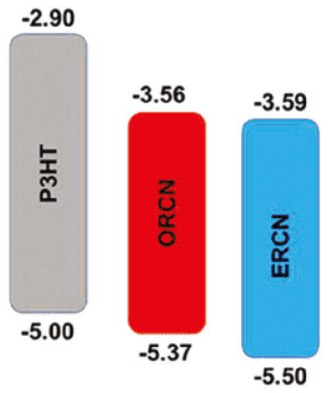

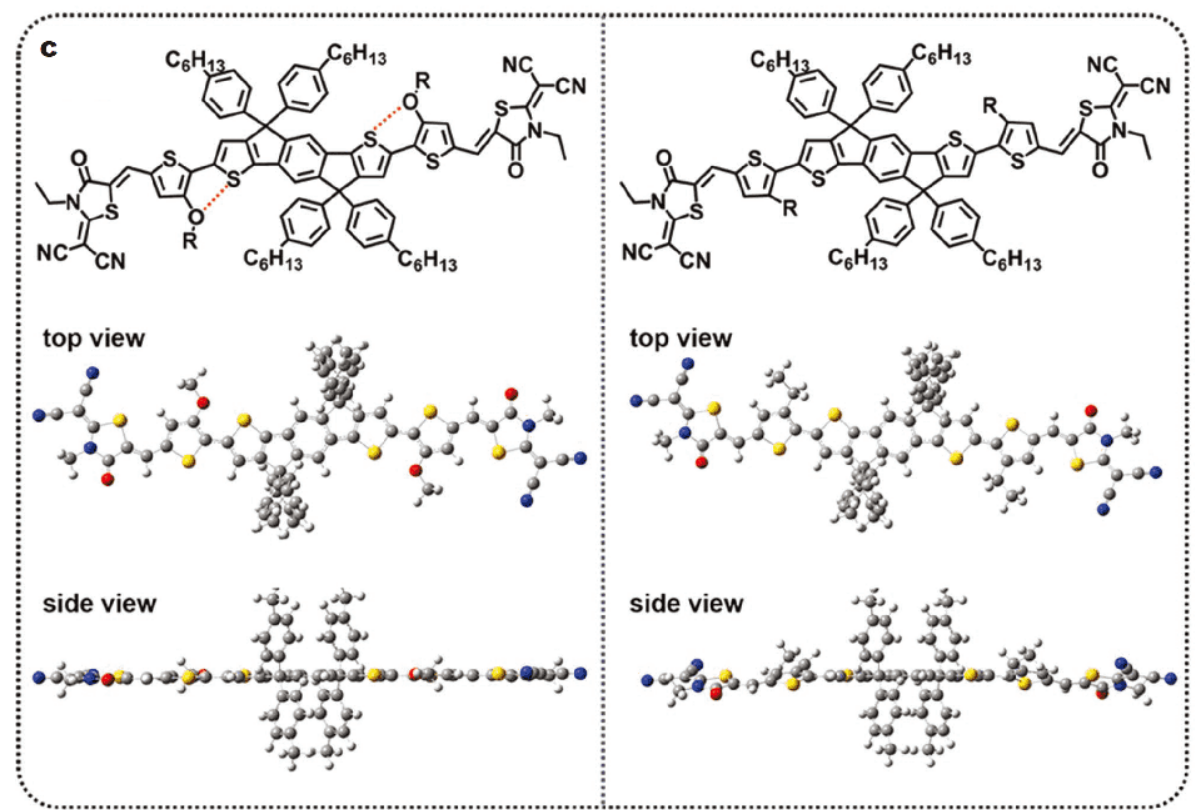

Figure 4 (a) UV-vis absorption spectra for the films of ERCN, ORCN, and P3HT. (b) Energy levels of P3HT, ORCN, and ERCN. (c) Molecular geometries of ORCN and ERCN obtained by DFT calculation. Reprinted with permission from Ref. [45]. Copyright 2018, Wiley-VCH.

As a result, the fabricated P3HT:ORCN OSCs demonstrated an impressive PCE of $6.6 \%$, attributed to the simultaneous enhancement of all device parameters compared with those of control ERCN-based device.

To further study the effect of NCLs, they further introduced thiazole $(\mathrm{Tz})$ as the $\pi$-conjugated bridge between IDT core and RD units to yield a new acceptor IDTzCR (Scheme 4, Table 3) [83]. In respect to the thiophene-bridged analogue IDTCR (Scheme 4, Table 3), the electron-withdrawing thiazole units can effectively lower the HOMO/LUMO energy levels and also increase the maximum absorption coefficient of IDTzCR. Moreover, due to the existence of S ‥N NCLs, the planarity/ rigidity of IDTzCR can also be increased to elevate the electron mobility and thus achieve more balanced electron/hole mobility in the $\mathrm{BHJ}$ blend. Through blending with PTB7-Th, the PCEs of derived OSCs were significantly improved from $6.10 \%$ (IDTCR) to $8.71 \%$
(IDTzCR). Recently, two new Tz-bridged small molecule NFAs, H-IDTzR and P-IDTzR (Scheme 4, Table 3), were also reported by integrating design strategy of NCLs with side-chain engineering [48]. Similarly, the S $\cdots N$ NCLs were found to enable good planar configuration in both acceptors, while the change of side-chains can affect the interchain $\pi-\pi$ stacking to tune the crystallinity. In comparison with H-IDTzR with $n$-hexyl side chains, PIDTzR with bulky 4-hexylphenyl side chains exhibited more suitable crystallinity to match with P3HT donor. As a result, a more optimal $\mathrm{BHJ}$ morphology can be realized in the P3HT:P-IDTzR blend to afford a higher PCE of $5.01 \%$.

Ester-substituted thieno[3,4- $b]$ thiophene $(\mathrm{T} b \mathrm{~T})$ unit is one of the most successful electron-withdrawing building blocks toward high-performance D-A type polymer donors such as PTB7-Th [84]. TbT unit typically exhibits a fully delocalized conjugation with a pronounced quinoid- 
enhancing effect, and its electron-withdrawing ester substitution can lower the HOMO/LUMO energy levels to improve the stability against oxidization $[4,85]$. Recently, ester-substituted $\mathrm{T} b \mathrm{~T}$ unit has been also used to construct efficient RD-based NFAs as the $\pi$-conjugated bridge and second A' moiety simultaneously. In 2016, Liu et al. [35] reported a new TbT-bridged acceptor ATT-1 (Scheme 4, Table 3) with IDT as the core and RCN as the end-groups, showing a low optical bandgap of $1.54 \mathrm{eV}$. The as-cast PTB7-Th:ATT-1 OSCs showed an impressive PCE up to $10.07 \%$ due to its proper energy level alignment, excellent carrier transport property and favorable BHJ film morphology. Soon after, they further synthesized ATT-3 (Scheme 4, Table 3) based on RD units [44]. ATT-3 exhibited a complementary absorption and wellmatched HOMO/LUMO energy levels with P3HT donor. Thus, the resulting P3HT:ATT-3 based OSCs showed a comparable PCE of $6.26 \%$ to the P3HT:O-IDTBR blend, due to the achievement of a higher $V_{\text {oc }}$ of $0.93 \mathrm{~V}$ and a smaller $E_{\text {loss }}$ of $0.68 \mathrm{eV}$. Very recently, another acceptor ATT-8 was also obtained based on the electron-withdrawing 2-(trifluoromethyl)thieno[3,4-b] thiophene unit (Scheme 4, Table 3), and the optimized OSCs based on the PBDB-T:ATT-8 blend afforded a high PCE to $7.31 \%$ with a $V_{\text {oc }}$ of $0.80 \mathrm{~V}$ and an FF of $65 \%$ [86].

Similarly, Xu and coworkers [87] recently reported two new NFAs, A1 and A2 (Scheme 4, Table 3), with low optical bandgaps below $1.40 \mathrm{eV}$, wherein ester-substituted benzothiadiazole (BTT) was used as the $\pi$-spacer. Compared with the BT-based analogous (IDT-2BR), the fused thiophene ring in the BTT unit can extend the conjugation length effectively to increase the quinoid population. Moreover, the ester substitution can also make the spacer electron-deficient, thereby forming the $A-A^{\prime}-D-A^{\prime}-A$ structure. These two structural changes can enable a more effective ICT effect to broaden the absorption and reduce the optical bandgap. Both NFAs realized good photovoltaic performance, and due to the enhanced light absorption resulted from RCN units, the corresponding A2based devices delivered a higher PCE of 9.07\% than that of A1-based one (5.79\%), with the same polymer donor PTB7-Th.

\section{NFAs with a hexacyclic electron-rich core}

Unlike the pentacyclic core, the hexacyclic core has been less studied for RD-based NFAs thus far. Given that the fused rings with angular shapes would lead to higherlying LUMO energy levels than the linear-shaped counterparts, Ma et al. [88] developed a new acceptor DTNR (Scheme 4, Table 3) based on a ladder-type angular- shaped dithienonaphthalene (DTN). DTNR had a higherlying LUMO energy level and an enhanced electron mobility compared with EH-IDTBR. Although the LUMO energy level offset between donor and acceptor was only $0.13 \mathrm{eV}$, the derived PTB7-Th:DTNR blend still showed a high PCE of $9.51 \%$ with a large $V_{\text {oc }}$ of $1.08 \mathrm{~V}$ and a low $E_{\text {loss }}$ of $0.50 \mathrm{eV}$, attributed to the efficient photoinduced charge separation.

\section{NFAs with a heptacyclic electron-rich core}

Replacing two thiophene rings in the IDT with TT units can afford a novel heptacyclic IDTT donor. This structural modification can significantly improve the charge mobility of the resulting IDTT-based molecules/polymers due to the extended effective conjugation length and enhanced intermolecular interactions [89]. Since the first demonstration of ITIC [10], IDTT has become the most studied core structure for A-D-A type NFAs [90]. Qu and coworkers [91] reported the synthesis of a series of new IDTT-RCN-based NFAs (ITBTR-C2, ITBTR-C4, ITBTR-C6, and ITBTRC8) (Scheme 5, Table 4) by tuning the side-chains in the RCN units including ethyl-, butyl-, hexyl-, and octyl- chains, respectively. Although all molecules exhibit similar absorption and HOMO/ LUMO energy levels, distinct photovoltaic performance has been realized with the same polymer donor PBDB-T, and in particular, the PBDB-T:ITBTR-C6 devices deliver the highest PCE of $8.26 \%$, attributed to its higher electron mobility and better phase separation morphology. Furthermore, by SVA, this PCE can be further increased to 9.29\% due to both enhancements of $J_{\mathrm{sc}}$ and FF. The results thus highlight the importance of introducing appropriate alkyl chains in the end-groups.

Further integrating IDTT core with BTA unit, Tang et al. [37] synthesized BTA13 (Scheme 5, Table 4), showing a larger maximum molar extinction coefficient, a redshifted optical absorption and elevated energy levels in comparison with the analogue BTA3. Paired with three BTA-based polymer donors (J52, J52-F and J52-FS, Scheme 1), the device performance of derived BTA13based OSCs was carefully optimized, and when blended with the fluorinated polymer donor J52-F, a highest PCE of $8.36 \%$ was demonstrated, benefited from the simultaneously achievement of high $V_{\text {oc }}$ and $J_{\text {sc. }}$ Song et al. [92] also reported another new NFA, DTFBR (Scheme 5, Table 4), by adopting fluorene-based heptacyclic donor as the core. When blended with P3HT, the derived OSCs showed a PCE of $3.68 \%$. Interestingly, blended with the fullerene acceptor $\mathrm{PC}_{71} \mathrm{BM}$, DTFBR can also work as a donor to deliver a PCE of $2.50 \%$, suggesting DTFBR is a 


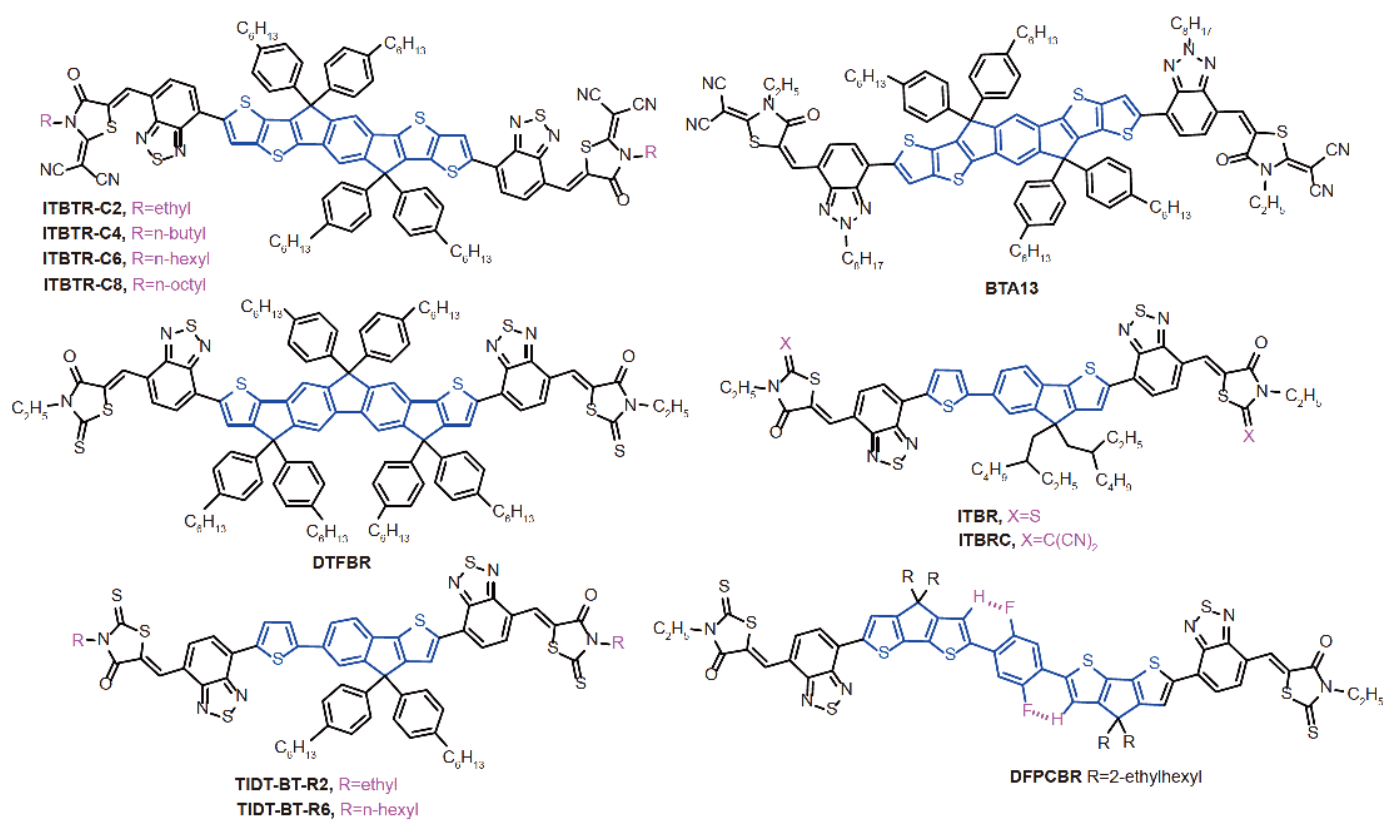

Scheme 5 Chemical structures of NFAs with a heptacyclic electron-rich core, and other type 1D NFAs.

Table 4 Summary of NFAs with a heptacyclic electron-rich core, and other type 1D NFAs

\begin{tabular}{|c|c|c|c|c|c|c|c|c|c|c|c|}
\hline \multirow{2}{*}{ NFAs } & \multirow{2}{*}{$\begin{array}{c}E_{\mathrm{HOMO}} \\
(\mathrm{eV})\end{array}$} & \multirow{2}{*}{$E_{\text {LUMO }}(\mathrm{eV})$} & \multirow{2}{*}{$E_{\mathrm{g}, \mathrm{opt}}(\mathrm{eV})$} & \multirow{2}{*}{ Donor } & \multirow{2}{*}{$V_{\mathrm{oc}}(\mathrm{V})$} & \multirow{2}{*}{$\left(\mathrm{mA} \mathrm{cm}^{J_{\mathrm{sc}}}\right)$} & \multirow{2}{*}{$\mathrm{FF}(\%)$} & \multirow{2}{*}{ PCE (\%) } & \multicolumn{2}{|c|}{ Mobility $\left(\mathrm{cm}^{2} \mathrm{~V}^{-1} \mathrm{~s}^{-1}\right)$} & \multirow{2}{*}{ Ref. } \\
\hline & & & & & & & & & Electron & Hole & \\
\hline ITBTR-C2 & $-5.30^{\mathrm{a}}$ & $-3.70^{\mathrm{a}}$ & 1.52 & PBDB-T & 0.89 & 13.47 & 59 & 7.04 & $8.6 \mathrm{E}-6$ & $3.2 \mathrm{E}-6$ & [91] \\
\hline ITBTR-C4 & $-5.30^{\mathrm{a}}$ & $-3.71^{\mathrm{a}}$ & 1.52 & PBDB-T & 0.90 & 14.94 & 55 & 7.43 & $2.4 \mathrm{E}-5$ & $1.9 \mathrm{E}-5$ & [91] \\
\hline ITBTR-C6 & $-5.30^{\mathrm{a}}$ & $-3.71^{\mathrm{a}}$ & 1.52 & PBDB-T & 0.88 & 16.30 & 64 & 9.29 & $6.6 \mathrm{E}-5$ & $6.0 \mathrm{E}-5$ & [91] \\
\hline ITBTR-C8 & $-5.28^{\mathrm{a}}$ & $-3.70^{\mathrm{a}}$ & 1.49 & PBDB-T & 0.90 & 14.88 & 59 & 7.93 & $3.4 \mathrm{E}-5$ & $2.8 \mathrm{E}-5$ & [91] \\
\hline \multirow[t]{3}{*}{ BTA13 } & $-5.34^{\mathrm{a}}$ & $-3.62^{\mathrm{c}}$ & 1.72 & $\mathrm{~J} 52$ & 1.05 & 12.70 & 59 & 7.82 & $2.8 \mathrm{E}-4$ & $5.9 \mathrm{E}-4$ & [37] \\
\hline & $-5.34^{\mathrm{a}}$ & $-3.62^{c}$ & 1.72 & $\mathrm{~J} 52-\mathrm{F}$ & 1.18 & 11.55 & 61 & 8.36 & $6.2 \mathrm{E}-5$ & $3.9 \mathrm{E}-4$ & [37] \\
\hline & $-5.34^{\mathrm{a}}$ & $-3.62^{\mathrm{c}}$ & 1.72 & J52-FS & 1.24 & 6.74 & 46 & 3.84 & $1.7 \mathrm{E}-5$ & $1.4 \mathrm{E}-4$ & [37] \\
\hline DTFBR & $-5.54^{\mathrm{a}}$ & $-3.68^{\mathrm{a}}$ & 1.74 & Р3HT & 0.71 & 8.15 & 62 & 3.68 & - & - & [92] \\
\hline ITBR & $-5.55^{\mathrm{a}}$ & $-3.71^{\mathrm{a}}$ & 1.71 & PTB7-Th & 1.02 & 14.46 & 51 & 7.49 & $1.5 \mathrm{E}-5$ & - & [93] \\
\hline ITBRC & $-5.60^{\mathrm{a}}$ & $-3.82^{\mathrm{a}}$ & 1.63 & PTB7-Th & 0.91 & 9.21 & 51 & 4.26 & $1.3 \mathrm{E}-5$ & - & [93] \\
\hline TIDT-BT-R2 & $-5.25^{\mathrm{a}}$ & $-3.65^{\mathrm{a}}$ & 1.68 & PTB7-Th & 1.04 & 13.10 & 64 & 8.70 & $2.5 \mathrm{E}-4$ & $2.7 \mathrm{E}-4$ & [94] \\
\hline TIDT-BT-R6 & $-5.28^{\mathrm{a}}$ & $-3.67^{\mathrm{a}}$ & 1.70 & PTB7-Th & 1.03 & 10.30 & 52 & 5.60 & $7.4 \mathrm{E}-5$ & $1.4 \mathrm{E}-4$ & [94] \\
\hline DFPCBR & $-5.12^{\mathrm{b}}$ & $-3.59^{\mathrm{b}}$ & 1.59 & P3HT & 0.80 & 10.39 & 64 & 5.34 & $1.0 \mathrm{E}-5$ & $8.6 \mathrm{E}-5$ & [47] \\
\hline
\end{tabular}

a) Measured by CV based on films. b) Measured by CV in solutions. c) Calculated by $E_{\mathrm{LUMO}}=E_{\mathrm{HOMO}}+E_{\text {g,opt. }}$ "” indicates that the details were not reported.

bipolar charge transport molecule.

\section{Other A-D-A type 1D NFAs}

In addition to these large fused-ring systems, a particular attention has been paid to designing core structure with single bonds interconnected aromatic rings, due to the low synthetic complexity. In 2017, Tang et al. [93] took advantage of the asymmetric thiophene-indenothiophene
(TIDT) unit as the core toward two new BT-bridged NFAs, ITBR and ITBRC (Scheme 5, Table 4), with RD and RCN as the end-groups, respectively. Inverted OSCs based on PTB7-Th:ITBR blend afforded a higher PCE of $7.49 \%$ with a lower $E_{\text {loss }}$ of $0.59 \mathrm{eV}$ than those based on PTB7-Th:ITBRC blend, due to its higher electron mobility and more suitable BHJ morphology. Later on, Bai and coworkers [94] also used the same core to synthesize 
TIDT-BT-R2 and TIDT-BTR6 (Scheme 5, Table 4), possessing complementary absorption and well-matched energy levels with PTB7-Th. Compared with TIDTBTR6, TIDT-BT-R2 with shorter ethyl side-chains showed better crystallinity and higher charge carrier mobilities in the BHJ blend. As a result, the PTB7-Th:TIDT-BT-R2 OSCs demonstrated much higher exciton dissociation efficiency and lower charge recombination, resulting in higher $J_{\mathrm{sc}}$ and FF to achieve a PCE up to $8.7 \%$.

Moreover, Wang and coworkers [47] recently reported a new RD-based NFA (DFPCBR, Scheme 5, Table 4) based on another non-fused core structure. In this molecule, the core structure was designed by linking two electron-rich cyclopentadithiophene (CPDT) units with a 2,5-difluorobenzene (DFB) ring. Due to the F...H noncovalent interactions between CDPT and DFB units, the core conformation can be locked effectively to form a largely planar geometry. DFPCBR exhibited a red-shifted absorption and higher-lying energy levels than EHIDTBR, which would enhance the light-harvesting ability and mitigate the energy loss of the resulting OSCs. Due to proper device optimizations, the P3HT:DFPCBR OSCs produced a decent PCE of 5.34\%. More encouragingly, it was found that almost $80 \%$ of the initial PCE can be remained even if the active layer thickness reached $320 \mathrm{~nm}$.

\section{A-D-A-TYPE 3D RD-BASED NFAs}

$3 \mathrm{D}$ structure design has been shown to enhance the compatibility of resulting NFAs with polymer donors desirably [95-97]. Besides, the acceptor aggregation in the $\mathrm{BHJ}$ blend can be also well-controlled through this molecular design. These two advantages thus would help to achieve preferred BHJ film morphology for charge separation/transport. So far, two major building blocks, spirofluorene and truxene, have been successfully developed as the core structure for constructing $3 \mathrm{D} \mathrm{RD}$-based NFAs.

In 2012, Ma et al. [98] first reported a spirofluorenecored 3D small molecule donor (SF8TBT). Compared with the linear analogue molecule (LF8TBT), the designed spirofluorene structure can enable optimized intermolecular stacking to increase the FF. Consequently, the SF8TBT:PC $\mathrm{P}_{71} \mathrm{BM}$ devices showed a dramatically increased PCE of $4.82 \%$ with an FF of 56\%. Until 2016, Qiu et al. [99] first used spirobifluorene as the central core to develop two 3D RD-based NFAs, SF-OR and SF-ORCN (Scheme 6, Table 5). Grazing-incidence X-ray diffraction (GIXD) measurements showed that such 3D conformation can effectively reduce the overall crystal packing in the $\mathrm{BHJ}$ blend with $\mathrm{P} 3 \mathrm{HT}$ donor and endow the derived blends with suitable phase separation to improve the device performance. In comparison with the corresponding linear molecule Flu-RH, SF-OR based OSCs afforded a higher PCE of $4.66 \%$ with an enhanced FF of $65 \%$. On the other hand, although the RCN end-groups can improve the light absorption, the derived SF-ORCNbased devices delivered a slightly decreased PCE of $4.48 \%$

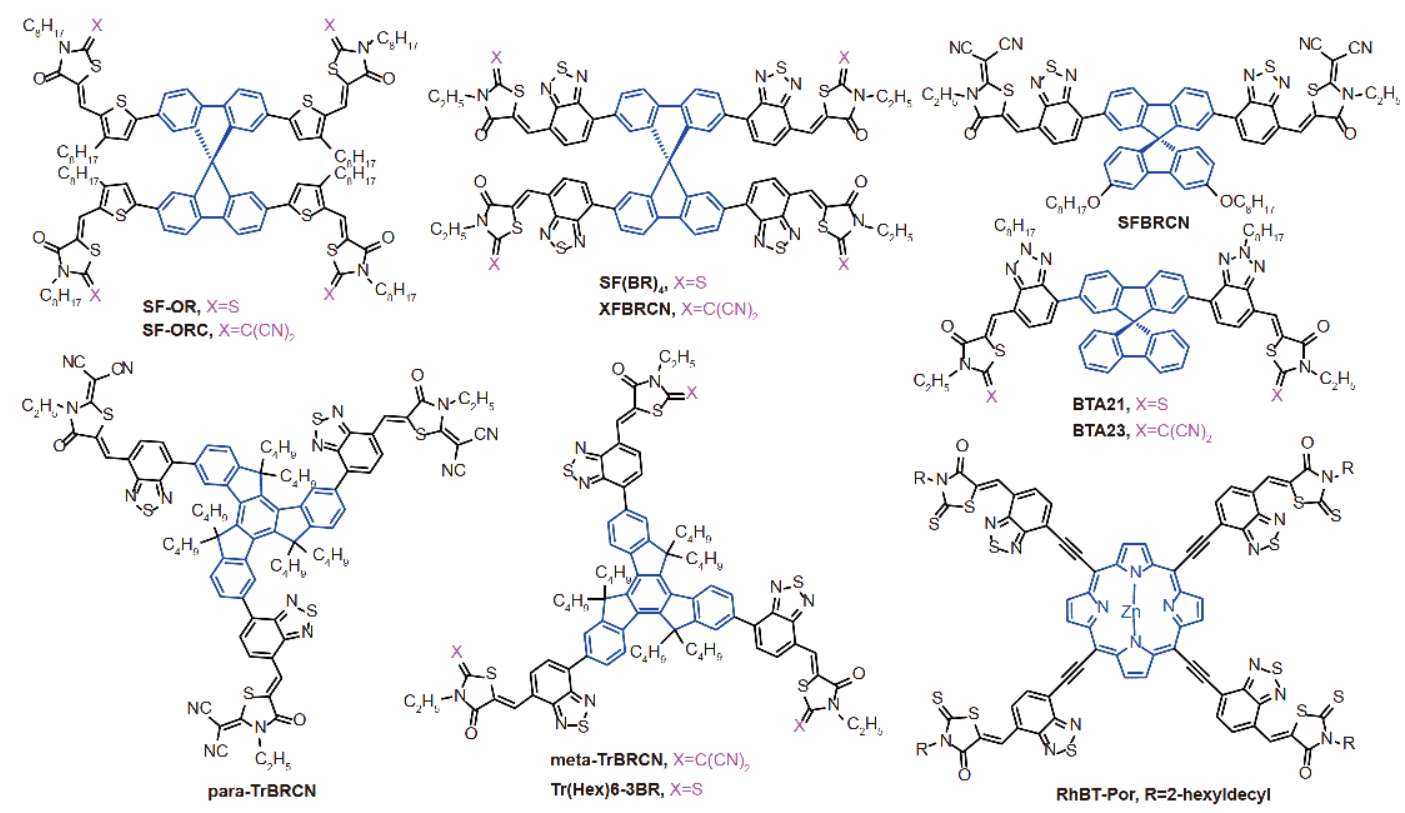

Scheme 6 Chemical structures of A-D-A-type 3D RD-based NFAs. 
Table 5 Summary of A-D-A-type 3D RD-based NFAs

\begin{tabular}{|c|c|c|c|c|c|c|c|c|c|c|c|}
\hline \multirow{2}{*}{ NFAs } & \multirow{2}{*}{$\begin{array}{c}E_{\text {HOMO }} \\
(\mathrm{eV})\end{array}$} & \multirow{2}{*}{$E_{\mathrm{LUMO}}(\mathrm{eV})$} & \multirow{2}{*}{$E_{\mathrm{g}, \mathrm{opt}}(\mathrm{eV})$} & \multirow{2}{*}{$\begin{array}{l}\text { Donor: } \\
\text { 2nd com- } \\
\text { ponent }\end{array}$} & \multirow{2}{*}{$V_{\mathrm{oc}}(\mathrm{V})$} & \multirow{2}{*}{$\left(\mathrm{mA} \mathrm{cm}^{J_{\mathrm{sc}}}\right)$} & \multirow{2}{*}{ FF (\%) } & \multirow{2}{*}{ PCE (\%) } & \multicolumn{2}{|c|}{ Mobility $\left(\mathrm{cm}^{2} \mathrm{~V}^{-1} \mathrm{~s}^{-1}\right)$} & \multirow{2}{*}{ Ref. } \\
\hline & & & & & & & & & Electron & Hole & \\
\hline SF-OR & $-5.50^{\mathrm{b}}$ & $-3.25^{\mathrm{b}}$ & 2.15 & P3HT & 0.96 & 7.44 & 65 & 4.66 & $6.7 \mathrm{E}-6$ & $8.5 \mathrm{E}-5$ & [99] \\
\hline SF-ORCN & $-5.55^{b}$ & $-3.29^{\mathrm{b}}$ & 2.08 & P3HT & 0.91 & 7.54 & 65 & 4.48 & $1.0 \mathrm{E}-4$ & $1.6 \mathrm{E}-4$ & [99] \\
\hline $\mathrm{SF}(\mathrm{BR})_{4}$ & $-5.78^{\mathrm{a}}$ & $-3.73^{\mathrm{a}}$ & 2.10 & $\begin{array}{l}\text { PffBT4T- } \\
\text { 2OD }\end{array}$ & 0.95 & 12.27 & 53 & 6.15 & $7.8 \mathrm{E}-5$ & $5.6 \mathrm{E}-4$ & [100] \\
\hline XFBRCN & $-5.89^{c}$ & $-3.77^{\mathrm{a}}$ & 2.12 & PTB7-Th & 0.91 & 4.60 & 34 & 1.42 & $3.0 \mathrm{E}-6$ & - & {$[65]$} \\
\hline \multirow[t]{3}{*}{ SFBRCN } & $-5.93^{\mathrm{a}}$ & $-3.86^{\mathrm{a}}$ & 2.05 & PTB7 & 0.85 & 14.00 & 61 & 7.63 & $1.2 \mathrm{E}-4$ & $5.5 \mathrm{E}-5$ & {$[101]$} \\
\hline & $-5.93^{\mathrm{a}}$ & $-3.86^{\mathrm{a}}$ & 2.05 & PTB7-Th & 0.90 & 17.80 & 64 & 10.26 & $2.2 \mathrm{E}-4$ & $1.5 \mathrm{E}-4$ & {$[101]$} \\
\hline & $-5.93^{\mathrm{a}}$ & $-3.86^{\mathrm{a}}$ & 2.05 & $\begin{array}{l}\text { PBDB-T: } \\
\text { PTB7-Th }\end{array}$ & 0.93 & 17.86 & 74 & 12.27 & $2.4 \mathrm{E}-4$ & $2.3 \mathrm{E}-4$ & [102] \\
\hline BTA21 & $-5.76^{\mathrm{a}}$ & $-3.56^{\mathrm{a}}$ & 2.19 & P3HT & 1.02 & 5.45 & 59 & 3.28 & $2.5 \mathrm{E}-6$ & $7.0 \mathrm{E}-6$ & [103] \\
\hline BTA23 & $-5.70^{\mathrm{a}}$ & $-3.64^{\mathrm{a}}$ & 2.15 & P3HT & 0.90 & 3.98 & 52 & 1.86 & $1.0 \mathrm{E}-6$ & $1.2 \mathrm{E}-7$ & {$[103]$} \\
\hline para-TrBRCN & $-5.98^{\mathrm{a}}$ & $-3.71^{\mathrm{a}}$ & 2.19 & PTB7-Th & 0.95 & 13.75 & 64 & 8.29 & $1.2 \mathrm{E}-4$ & $6.5 \mathrm{E}-5$ & {$[34]$} \\
\hline \multirow[t]{2}{*}{ meta-TrBRCN } & $-5.95^{\mathrm{a}}$ & $-3.72^{\mathrm{a}}$ & 2.10 & PTB7-Th & 0.94 & 16.75 & 65 & 10.15 & $2.0 \mathrm{E}-4$ & $1.3 \mathrm{E}-4$ & {$[34]$} \\
\hline & $-5.95^{\mathrm{a}}$ & $-3.72^{\mathrm{a}}$ & 2.10 & $\begin{array}{l}\text { PDTF- } \\
\text { TZNT: } \\
\text { IT-M }\end{array}$ & 0.82 & 18.54 & 76 & 11.48 & - & - & [105] \\
\hline $\operatorname{Tr}(\mathrm{Hex}) 6-3 \mathrm{BR}$ & $-5.79^{\mathrm{a}}$ & $-3.74^{\mathrm{a}}$ & 2.15 & PTB7-Th & 1.02 & 5.92 & 33 & 2.10 & $1.5 \mathrm{E}-5$ & $1.5 \mathrm{E}-3$ & {$[104]$} \\
\hline RhBT-Por & $-5.48^{\mathrm{a}}$ & $-3.55^{\mathrm{a}}$ & 1.45 & PDPP5T & 0.54 & 7.40 & 47 & 1.9 & $2.6 \mathrm{E}-5$ & $5.0 \mathrm{E}-5$ & [106] \\
\hline
\end{tabular}

a) Measured by CV based on films. b) Measured by CV in solutions. c) Calculated by $E_{\mathrm{LUMO}}=E_{\mathrm{HOMO}}+E_{\mathrm{g}, \mathrm{opt}}$ " - ” indicates that the details were not reported.

mainly due to the inferior $V_{\text {oc. }}$.

Later on, Tan and coworkers [100] further reported $\mathbf{S F}(\mathbf{B R})_{4}$ (Scheme 6, Table 5) by introducing four BT units between the spirobifluorene core and the RD endgroups. $\quad \mathbf{S F}(\mathbf{B R})_{4}$ exhibited significantly downshifted HOMO/LUMO energy levels in comparison with SF-OR, making it more compatible with low-bandgap polymer donor, PffBT4T-2OD. Furthermore, the 3D molecular geometry of $\mathbf{S F}(\mathbf{B R})_{4}$ was found to suppress the strong intermolecular aggregation efficiently after forming a PffBT4T-2OD:SF(BR ${ }_{4}$ blend. As a result, a respectable PCE of $6.15 \%$ can be achieved. Meanwhile, a new RCNbased 3D acceptor XFBRCN was also synthesized by Radford et al. [65] (Scheme 6, Table 5). Time-dependent density functional theory (TDDFT) showed that the dynamic torsion of spirobifluorene core could lead to a small amount of exciton coupling at room temperature. XFBRCN had a broader absorption, a higher extinction coefficient and a higher permittivity than the linear analogue fluorene-cored FBRCN (Scheme 2, Table 1), but showed an inferior PCE of $1.42 \%$ compared with that of latter (3.3\%). Further mechanism studies showed that the long alkyl chain substitutions on the fluorene core of FBRCN not only facilitated the intermolecular packing in the solid-state to improve the electron mobility, but also provided more miscibility with polymer donors to ensure well-defined domain size in the blend, both of which therefore can effectively reduce the non-geminate recombination of the derived PTB7-Th:FBRCN blend to improve the $J_{\text {sc. }}$.

In addition, several 3D NFAs were also designed by end-capping $\mathrm{RD}$ units only onto two sides of spirofluorene. In 2017, Zhang and coworkers [101] adopted an alkoxy-substituted spirofluorene as the core to synthesize a wide bandgap NFA, SFBRCN (Scheme 6, Table 5). In the SFBRCN, a planar conjugated backbone can help to realize high charge mobility, while the $3 \mathrm{D}$ spirobifluorene core can reduce its self-aggregation tendency to induce an optimal domain size in the $\mathrm{BHJ}$ blend. Furthermore, the deep HOMO $(-5.93 \mathrm{eV})$ and LUMO $(-3.86 \mathrm{eV})$ levels of SFBRCN can match well with both polymer donors of PTB7 and PTB7-Th, and the resulting PTB7-Th: SFBRCN-based PSCs realized a higher PCE of $10.12 \%$. Later on, they also fabricated PBDB-T:PTB7-Th:SFBRCN based ternary OSCs, showing an impressive PCE of $12.27 \%$ [102]. Based on this, Wen et al. [103] prepared two BTA-bridged 3D acceptors, BTA21 and BTA23 (Scheme 6, Table 5), having wide optical bandgaps of 2.19 and $2.15 \mathrm{eV}$, respectively. Compared with BTA23, the resulting BTA21 based OSCs showed a better PCE of 
$3.28 \%$ with a high $V_{\text {oc }}$ of $1.02 \mathrm{~V}$ due to its more compatible energy levels and absorption with respect to P3HT.

Using the weak electron-donating truxene as the central core, $\mathrm{Wu}$ and coworkers [34] further designed and synthesized two RCN-based isomeric 3D NFAs, paraTrBRCN and meta-TrBRCN (Scheme 6, Table 5). These two star-shaped acceptors exhibited a nonplanar structure due to the large dihedral angles between the truxene skeleton and the connecting BT units (Fig. 5), which was shown to prevent the excessive aggregation of acceptor molecules in the BHJ blend to realize optimized film morphology and ideal domain size. Compared with that of para-TrBRCN, the smaller structure distortion of meta-TrBRCN can enhance the intermolecular $\pi-\pi$ stacking to improve the charge transfer. Therefore, when blended with the same donor PTB7-Th, meta-TrBRCNbased OSCs delivered a higher PCE compared with the para-TrBRCN-based devices ( $10.15 \%$ vs. $8.28 \%)$. By contrast, Lin et al. [104] also reported an RD-based analogue $\operatorname{Tr}($ Hex)6-3BR (Scheme 6, Table 5), which, however, only showed a PCE of $2.10 \%$, attributed to low electron mobility, serious charge recombination and unfavorable BHJ film morphology. Soon after, Tang et al. [105] further introduced meta-TrBRCN as the second acceptor to fabricate the PDTF-TZNT:IT-M:metaTrBRCN ternary OSCs. It was found that in the formed ternary blend, meta-TrBRCN not only expanded the absorption range, but also finely tuned the blend morphology. Thus, when adding $20 \%$ content of metaTrBRCN, the PCE can be improved from $10.05 \%$ to $11.48 \%$.

Moreover, Guo et al. [106] adopted the zinc-coordinated porphyrin molecule as the electron-rich core to develop a new star-shaped RD-based NFA, RhBT-Por (Scheme 6, Table 5), possessing three distinct absorption regions due to the Soret and Q-bands of the porphyrin and the ICT between the porphyrin core and the RD end-

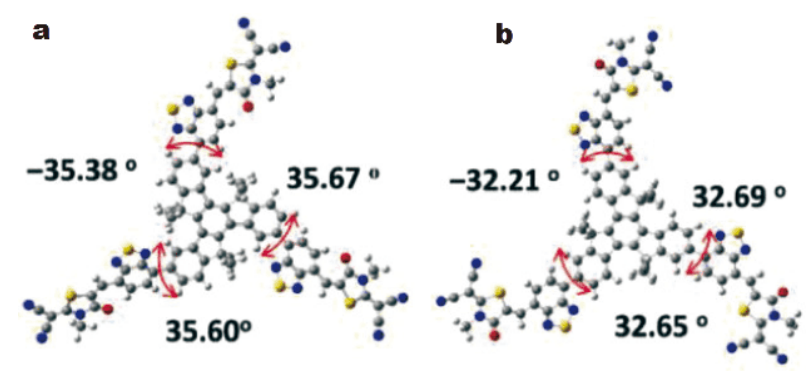

Figure 5 Optimized molecular geometries of para-TrBRCN (a) and meta-TrBRCN (b). Reprinted with permission from Ref. [34]. Copyright 2018, Wiley-VCH. groups. A very broad photo-response from 300 to $850 \mathrm{~nm}$ can be achieved when blended with a DPP-based conjugated polymer donor, PDPP5T (Scheme 1); however a low PCE of $1.9 \%$ was yielded possibly due to the unideal BHJ morphology.

\section{OTHER-TYPE RD-BASED NFAs}

Recently, Lee and coworkers [107] reported a simple RDbased NFA, T2-ORH (Scheme 7, Table 6), wherein a bithiophene core was end-capped by two octyl-substituted RD units. In addition to the previously discussed A-D-A or A-A'-D-A'-A type structure, T2-ORH could be regarded as an A- $\pi$-A type structure with a very short $\pi$ conjugation length. T2-ORH exhibited a wide bandgap, and a blue-shifted absorption can be observed in the pristine film state due to the formation of $H$-like aggregation. Interestingly, during device fabrication, thermal annealing (TA) or SVA was found to enable T2-ORH to form a $J$-like aggregation in the $\mathrm{BHJ}$ film, accompanied with a red-shifted absorption. As a result, the derived PTB7-Th:T2-ORH blend films can feature both vertical and parallel charge transport channels to improve the device performance, and the corresponding additive-free OSCs delivered an impressive PCE of $9.33 \%$ with a low $E_{\text {loss }}$ of $0.51 \mathrm{eV}$.

Besides, a new A-A'-A type acceptor, ISDT-RH (Scheme 7, Table 6) with an electro-deficient isoindigo core was reported by Kim and coworkers in 2016 [108]. The pristine ISDT-RH film showed a strong absorption in a range of $350-650 \mathrm{~nm}$ with a maximal extinction coefficient of $8.0 \times 10^{4} \mathrm{~cm}^{-1}$ at $465 \mathrm{~nm}$. The HOMO and LUMO energy levels of ISDT-RH were determined to be -5.59 and $-3.82 \mathrm{eV}$, respectively. Unfortunately, the fabricated P3HT:ISDT-RH devices only gave a PCE as low as $0.42 \%$.

Later on, Privado et al. [109-111] successfully synthesized three new DPP-cored acceptors with A-A'-A type structure, MPU1-3 (Scheme 7, Table 6). MPU1 exhibited a narrow optical bandgap $(1.48 \mathrm{eV})$ and a low-lying LUMO level of $-3.99 \mathrm{eV}$. When blended with a medium bandgap D-A copolymer donor P2 $(1.75 \mathrm{eV})$, the derived MPU1-based OSCs showed a broad photo response covering from 400 to $850 \mathrm{~nm}$ to enable an impressive PCE of 7.5\%, much higher than that of P3HT:MPU1based devices $(2.16 \%)$ under similar fabrication conditions. Moreover, the RCN-capped MPU2 presented a broad absorption with a reduced optical energy gap of $1.41 \mathrm{eV}$, and a lower-lying LUMO level of $-4.15 \mathrm{eV}$ compared with MPU1. The higher electron withdrawing ability of RCN can endow a higher electron mobility for 


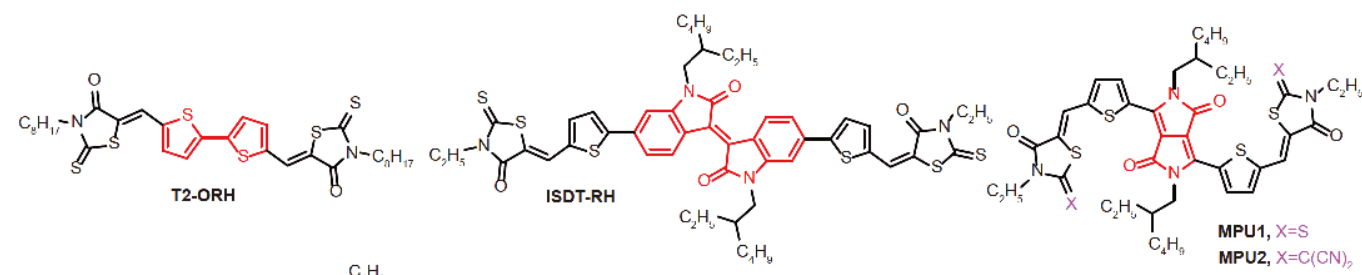

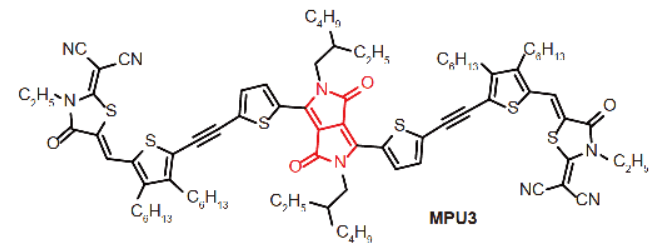
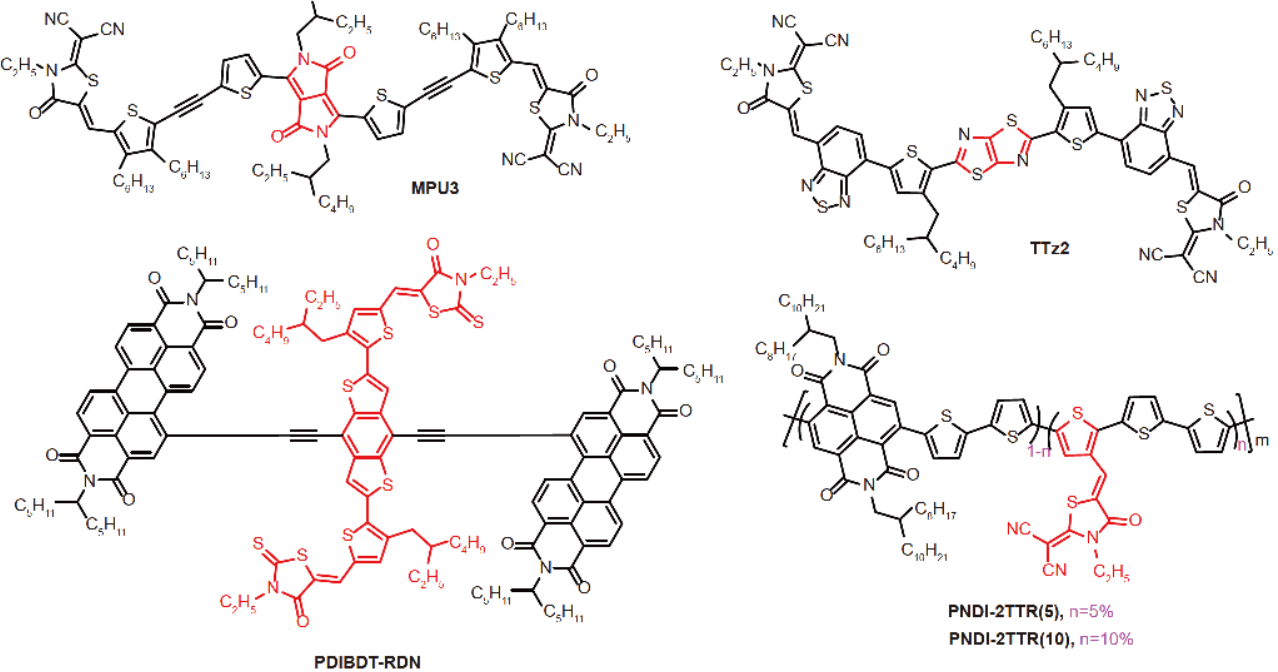

Scheme 7 Chemical structures of other-type RD-based NFAs.

Table 6 Summary of other-type RD-based NFAs

\begin{tabular}{|c|c|c|c|c|c|c|c|c|c|c|c|}
\hline \multirow{2}{*}{ NFAs } & \multirow{2}{*}{$\begin{array}{c}E_{\text {HOMO }} \\
(\mathrm{eV})\end{array}$} & \multirow{2}{*}{$E_{\text {LUMO }}(\mathrm{eV})$} & \multirow{2}{*}{$E_{\mathrm{g}, \mathrm{opt}}(\mathrm{eV})$} & \multirow{2}{*}{ Donor } & \multirow{2}{*}{$V_{\mathrm{oc}}(\mathrm{V})$} & \multirow{2}{*}{$\left(\mathrm{mA} \mathrm{cm}^{J_{\mathrm{sc}}}\right)$} & \multirow{2}{*}{$\mathrm{FF}(\%)$} & \multirow{2}{*}{ PCE (\%) } & \multicolumn{2}{|c|}{ Mobility $\left(\mathrm{cm}^{2} \mathrm{~V}^{-1} \mathrm{~s}^{-1}\right)$} & \multirow{2}{*}{ Ref. } \\
\hline & & & & & & & & & Electron & Hole & \\
\hline T2-ORH & $-5.89^{\mathrm{a}}$ & $-3.64^{\mathrm{a}}$ & 2.03 & PTB7-Th & 1.07 & 14.72 & 59 & 9.33 & $9.0 \mathrm{E}-4$ & $2.1 \mathrm{E}-3$ & [107] \\
\hline ISDT-RH & $-5.59^{\mathrm{a}}$ & $-3.82^{\mathrm{a}}$ & 1.77 & P3HT & 0.58 & 1.77 & - & 0.42 & - & - & [108] \\
\hline ISDT-ECA & $-5.56^{\mathrm{a}}$ & $-3.61^{\mathrm{a}}$ & 1.95 & P3HT & 0.68 & 1.47 & - & 0.53 & - & - & {$[108]$} \\
\hline \multirow[t]{3}{*}{ MPU1 } & $-5.81^{\mathrm{b}}$ & $-3.99^{\mathrm{b}}$ & 1.48 & $\mathrm{P} 2$ & 0.98 & 12.37 & 62 & 7.52 & - & - & [109] \\
\hline & $-5.81^{\mathrm{b}}$ & $-3.99^{b}$ & 1.48 & P3HT & 0.60 & 6.54 & 55 & 2.16 & - & - & [109] \\
\hline & $-5.81^{\mathrm{b}}$ & $-3.99^{b}$ & 1.48 & $\begin{array}{c}\text { DTS } \\
\left(\mathrm{QxHTh}_{2}\right)_{2}\end{array}$ & 1.02 & 11.04 & 62 & 6.98 & - & - & [110] \\
\hline MPU2 & $-5.72^{\mathrm{b}}$ & $-4.15^{\mathrm{b}}$ & 1.41 & $\begin{array}{c}\text { DTS } \\
\left(\mathrm{QxHTh}_{2}\right)_{2}\end{array}$ & 0.94 & 12.15 & 68 & 7.76 & $7.1 \mathrm{E}-5$ & $1.2 \mathrm{E}-4$ & [110] \\
\hline MPU3 & $-5.61^{b}$ & $-3.74^{\mathrm{b}}$ & 1.52 & $\begin{array}{c}\text { p-DINI- } \\
\left(\text { FBTTTH }_{3}\right)_{2}\end{array}$ & 0.98 & 13.72 & 67 & 9.14 & 7.9E-5 & $1.2 \mathrm{E}-4$ & [111] \\
\hline TTz2 & $-5.50^{\mathrm{a}}$ & $-3.80^{\mathrm{a}}$ & 1.61 & $\mathrm{~J} 71$ & 0.92 & 12.75 & 54 & 6.30 & $8.7 \mathrm{E}-5$ & $2.9 \mathrm{E}-4$ & {$[112]$} \\
\hline $\begin{array}{l}\text { PDIBDT- } \\
\text { RDN }\end{array}$ & $-5.86^{\mathrm{a}}$ & $-3.81^{\mathrm{a}}$ & 1.64 & PTB7-Th & 0.76 & 9.28 & 47 & 3.34 & $2.9 \mathrm{E}-5$ & $1.5 \mathrm{E}-3$ & [113] \\
\hline $\begin{array}{l}\text { PNDI-2T-TR } \\
\text { (5) }\end{array}$ & $-5.91^{\mathrm{a}}$ & $-3.91^{\mathrm{a}}$ & 1.48 & PBDB-T & 0.85 & 14.83 & 64 & 8.13 & $3.9 \mathrm{E}-4$ & $6.5 \mathrm{E}-4$ & [116] \\
\hline $\begin{array}{l}\text { PNDI-2TTR } \\
\quad(10)\end{array}$ & $-5.92^{\mathrm{a}}$ & $-3.93^{\mathrm{a}}$ & 1.50 & PBDB-T & 0.80 & 11.36 & 54 & 4.89 & $1.2 \mathrm{E}-4$ & $8.5 \mathrm{E}-4$ & [116] \\
\hline
\end{tabular}

a) Measured by CV based on films. b) Measured by CV in solutions. “-” indicates that the details were not reported.

MPU2. Consequently, when paired with a small molecular donor DTS $\left(\mathrm{QxHTh}_{2}\right)_{2}$ (Scheme 1), the vacuumprocessing MPU2-based OSCs delivered a higher PCE of
7.76\% than that of the control MPU1-based devices (6.28\%).

Further introduction of hexyl-substituted thienylethy- 
nyl group between the DPP core and the RCN units as the $\pi$-conjugated bridge afforded a new $A-\pi-A^{\prime}-\pi$-A type acceptor, MPU3. In comparison with MPU2, the additional thienylethynyl bridge can broaden the ICT band, accompanied with a higher molar extinction coefficient. Nonetheless, MPU3 exhibited a larger optical bandgap of $1.52 \mathrm{eV}$ than MPU1-2. The MPU3-based OSCs delivered an impressive PCE of $9.05 \%$ with a small molecule donor p-DINI-(FBTTTh $)_{2}$ (Scheme 1), greatly outperforming the p-DINI-(FBTTTh $)_{2}: \mathrm{PC}_{71} \mathrm{BM}(5.80 \%)$ devices, mainly due to that MPU3-based devices showed a much lower $E_{\text {loss }}$ of $0.54 \mathrm{eV}$ by comparison with the $\mathrm{PC}_{71} \mathrm{BM}$-based counterpart $(1.02 \mathrm{eV})$ as a result of the significantly decreased LUMO offset between p-DINI-(FBTTTh $\left.{ }_{3}\right)_{2}$ and MPU3.

In 2018, Peng and coworkers [112] also synthesized a medium bandgap RD-based A- $\pi-A^{\prime}-\pi-A$ type NFA, TTz2 (Scheme 7, Table 6), using a weakly electron-deficient thiazolothiazole $(\mathrm{TTz})$ unit as the core. The HOMO/ LUMO energy levels of TTz2 were very compatible with those of polymer donor J71, and thus the fabricated devices exhibited a good PCE of $6.30 \%$.

Recently, Liu et al. [113] developed an interesting crossconjugated NFA based on a BDT core, PDIBDT-RDN (Scheme 7, Table 6). In this structure, the BDT unit was flanked by two different kinds of electron-withdrawing moieties (perylene diimides and 3-ethylrhodanine units). PDIBDT-RDN presented low-lying HOMO/LUMO energy levels and a broad absorption band ranging from 300 to $700 \mathrm{~nm}$. With the polymer donor PTB7-Th, the derived PDIBDT-RDN-based OSCs delivered a PCE of $3.34 \%$, which was mainly limited by the low $J_{\text {sc }}$ and FF.

Naphthalene diimide (NDI)-based polymer acceptors, such as N2200 [114,115], has been widely used in allpolymer solar cells (all-PSCs); however, their low light absorption, suboptimal energy levels and strong self-aggregation have retarded the further elevation of device performance. To resolve this problem, Chen et al. [116] introduced a RD-based dye molecule into the NDI-based polymer acceptor through a simple random copolymerization. The new NDI-based polymer acceptors (PNDI$2 \operatorname{TTR}(x),(x=5$ and 10 , Scheme 7 , Table 6$)$, with a dye of content of $5 \%$ and $10 \%$, respectively, showed enhanced light absorption, up-shifted LUMO levels and reduced crystallization in comparison with N2200. In addition, the bimolecular and monomolecular recombination can be suppressed substantially in the PNDI-2TTR(5)-based devices. As a result, a high PCE of $8.13 \%$ was achieved from the additive-free PBDB-T:PNDI-2T-TR(5) based OSCs, much higher than that of N2200-based devices.
Unfortunately, the PBDB-T:PNDI-2T-TR(10)-based OSCs only showed a PCE of $\sim 5 \%$ due to the unfavorable blend morphology caused by disordered molecular packing. These results therefore suggest that the polymer structure from such random polymerization strategy needs to be controlled carefully.

\section{SUMMARY AND PERSPECTIVE}

In summary, RD dye and its derivatives have been successfully used as the electron-withdrawing moieties to construct high-performance A-D-A type NFAs. When blended with well-known narrow bandgap polymer donor PTB7-Th and medium bandgap polymer donor PffBT2T-TT, the derived binary OSCs based on RDbased NFAs both have shown encouraging PCEs over $10 \%$ [33,75]. Although the device performance is still lower than that of other state-of-the-art INCN-based NFAs, RD-based NFAs have demonstrated a particularly excellent compatibility with well-known P3HT donor. The optimized P3HT:O-IDTBR OSCs have achieved a record PCE of 7.0\% in single-junction binary devices [49]. So far, P3HT has always been considered as one of the few feasible polymer donors suitable for large-scale commercialization of OSCs, due to its simple synthesis and monomer availability. In this context, more novel molecular designs of RD-based NFAs with suitable energy levels, complementary absorption and favorable molecular crystallinity should be continuously developed.

Recently, a new D-A-D type fused core structure was designed to construct NFAs, affording very exciting PCEs up to $16 \%$ [13-15]. These encouraging results manifest that the core structure engineering can provide an ample room to further boost the performance of NFAs. Indeed, both non-fused and simple A- $\pi$-A-type RD-based NFAs have been reported with very good performance. Furthermore, other suitable structural modifications, like side-chain engineering and introduction of the second acceptor units, need to be taken into account carefully in parallel with the development of new core structure. For $\mathrm{RD}$ itself, it is worthwhile to mention that its 2-position can be further functionalized by different aromatic rings, which may provide a new approach to tune the optical/ electronic properties and the intermolecular stacking behaviors of the resulting NFAs. We believe that through a rational molecular design, PCEs over $10 \%$ could be achieved for RD-based NFAs with the P3HT donor in the near future.

On the other hand, the properties related to absorption and energy levels of RD-based NFAs also make them a class of potential third component materials in the tern- 
ary OSCs. Besides, the OSCs derived from RD-based NFAs always exhibit a high $V_{\text {oc }}$ over $1.0 \mathrm{~V}$, suggesting that they could be suitable material candidates for fabricating high-performance tandem OSCs. From these points of view, we have to also pay particular attention to exploring new design strategies of RD-based NFAs to fulfill the requirements of these advanced devices.

\section{Received 19 May 2019; accepted 25 June 2019; published online 24 July 2019}

1 Tang CW. Two-layer organic photovoltaic cell. Appl Phys Lett, 1986, 48: 183-185

2 Sariciftci NS, Smilowitz L, Heeger AJ, et al. Photoinduced electron transfer from a conducting polymer to buckminsterfullerene. Science, 1992, 258: 1474-1476

3 Dou L, You J, Hong Z, et al. 25th Anniversary article: A decade of organic/polymeric photovoltaic research. Adv Mater, 2013, 25: 6642-6671

4 Lu L, Zheng T, Wu Q, et al. Recent advances in bulk heterojunction polymer solar cells. Chem Rev, 2015, 115: 12666-12731

5 Li M, Gao K, Wan X, et al. Solution-processed organic tandem solar cells with power conversion efficiencies $>12 \%$. Nat Photon, 2016, 11: 85-90

6 Zhao J, Li Y, Yang G, et al. Efficient organic solar cells processed from hydrocarbon solvents. Nat Energy, 2016, 1: 15027

7 Gélinas S, Rao A, Kumar A, et al. Ultrafast long-range charge separation in organic semiconductor photovoltaic diodes. Science, 2014, 343: 512-516

8 Ganesamoorthy R, Sathiyan G, Sakthivel P. Review: Fullerene based acceptors for efficient bulk heterojunction organic solar cell applications. Sol Energy Mater Sol Cells, 2017, 161: 102-148

9 Baran D, Kirchartz T, Wheeler S, et al. Reduced voltage losses yield $10 \%$ efficient fullerene free organic solar cells with $>1 \mathrm{~V}$ open circuit voltages. Energy Environ Sci, 2016, 9: 3783-3793

10 Lin Y, Wang J, Zhang ZG, et al. An electron acceptor challenging fullerenes for efficient polymer solar cells. Adv Mater, 2015, 27: 1170-1174

11 Zheng Z, Awartani OM, Gautam B, et al. Efficient charge transfer and fine-tuned energy level alignment in a THF-processed fullerene-free organic solar cell with $11.3 \%$ efficiency. Adv Mater, 2017, 29: 1604241

12 Cui Y, Yao H, Hong L, et al. Achieving over 15\% efficiency in organic photovoltaic cells via copolymer design. Adv Mater, 2019, 31: 1808356

13 An Q, Ma X, Gao J, et al. Solvent additive-free ternary polymer solar cells with $16.27 \%$ efficiency. Sci Bull, 2019, 64: 504-506

14 Fan B, Zhang D, Li M, et al. Achieving over $16 \%$ efficiency for single-junction organic solar cells. Sci China Chem, 2019, 62: 746-752

15 Yuan J, Zhang Y, Zhou L, et al. Single-junction organic solar cell with over $15 \%$ efficiency using fused-ring acceptor with electrondeficient core. Joule, 2019, 3: 1140-1151

16 Meng L, Zhang Y, Wan X, et al. Organic and solution-processed tandem solar cells with $17.3 \%$ efficiency. Science, 2018, 361: 1094-1098

17 Zhang G, Zhao J, Chow PCY, et al. Nonfullerene acceptor molecules for bulk heterojunction organic solar cells. Chem Rev,
2018, 118: 3447-3507

18 Lin $\mathrm{Y}, \mathrm{He} \mathrm{Q}$, Zhao F, et al. A facile planar fused-ring electron acceptor for as-cast polymer solar cells with $8.71 \%$ efficiency. J Am Chem Soc, 2016, 138: 2973-2976

19 Lin Y, Li T, Zhao F, et al. Structure evolution of oligomer fusedring electron acceptors toward high efficiency of as-cast polymer solar cells. Adv Energy Mater, 2016, 6: 1600854

20 Zhao W, Li S, Yao H, et al. Molecular optimization enables over 13\% efficiency in organic solar cells. J Am Chem Soc, 2017, 139: 7148-7151

21 Kan B, Feng H, Wan X, et al. Small-molecule acceptor based on the heptacyclic benzodi(cyclopentadithiophene) unit for highly efficient nonfullerene organic solar cells. J Am Chem Soc, 2017, 139: 4929-4934

22 Liu T, Gao W, Wang Y, et al. Unconjugated side-chain engineering enables small molecular acceptors for highly efficient non-fullerene organic solar cells: Insights into the fine-tuning of acceptor properties and micromorphology. Adv Funct Mater, 2019, 361: 1902155

23 Winzenberg KN, Kemppinen P, Scholes FH, et al. Indan-1,3dione electron-acceptor small molecules for solution-processable solar cells: A structure-property correlation. Chem Commun, 2013, 49: 6307-6309

24 Kim Y, Song CE, Moon SJ, et al. Effect of dye end groups in nonfullerene fluorene- and carbazole-based small molecule acceptors on photovoltaic performance. RSC Adv, 2015, 5: 62739-62746

25 Gao HH, Sun Y, Wan X, et al. Design and synthesis of low band gap non-fullerene acceptors for organic solar cells with impressively high $J_{\mathrm{sc}}$ over $21 \mathrm{~mA} \mathrm{~cm}{ }^{-2}$. Sci China Mater, 2017, 60: 819-828

26 Li C, Xie Y, Fan B, et al. A nonfullerene acceptor utilizing a novel asymmetric multifused-ring core unit for highly efficient organic solar cells. J Mater Chem C, 2018, 6: 4873-4877

27 Song J, Li C, Ye L, et al. Extension of indacenodithiophene backbone conjugation enables efficient asymmetric A-D-A type non-fullerene acceptors. J Mater Chem A, 2018, 6: 18847-18852

28 Fan Q, Su W, Wang Y, et al. Synergistic effect of fluorination on both donor and acceptor materials for high performance nonfullerene polymer solar cells with $13.5 \%$ efficiency. Sci China Chem, 2018, 61: 531-537

29 Kan B, Feng H, Yao H, et al. A chlorinated low-bandgap smallmolecule acceptor for organic solar cells with $14.1 \%$ efficiency and low energy loss. Sci China Chem, 2018, 61: 1307-1313

30 Xiao L, He B, Hu Q, et al. Multiple roles of a non-fullerene acceptor contribute synergistically for high-efficiency ternary organic photovoltaics. Joule, 2018, 2: 2154-2166

31 Zuo L, Shi X, Jo SB, et al. Tackling energy loss for high-efficiency organic solar cells with integrated multiple strategies. Adv Mater, 2018, 30: 1706816

32 Baran D, Ashraf RS, Hanifi DA, et al. Reducing the efficiencystability-cost gap of organic photovoltaics with highly efficient and stable small molecule acceptor ternary solar cells. Nat Mater, 2017, 16: 363-369

33 Suman S, Bagui A, Garg A, et al. A fluorene-core-based electron acceptor for fullerene-free BHJ organic solar cells-towards power conversion efficiencies over $10 \%$. Chem Commun, 2018, 54: 4001-4004

$34 \mathrm{Wu}$ W, Zhang G, Xu X, et al. Wide bandgap molecular acceptors with a truxene core for efficient nonfullerene polymer solar cells: Linkage position on molecular configuration and photovoltaic 
properties. Adv Funct Mater, 2018, 28: 1707493

35 Liu F, Zhou Z, Zhang C, et al. A thieno[3,4- $b]$ thiophene-based non-fullerene electron acceptor for high-performance bulk-heterojunction organic solar cells. J Am Chem Soc, 2016, 138: $15523-15526$

36 Liu F, Zhou Z, Zhang C, et al. Efficient semitransparent solar cells with high NIR responsiveness enabled by a small-bandgap electron acceptor. Adv Mater, 2017, 29: 1606574

37 Tang A, Xiao B, Chen F, et al. The introduction of fluorine and sulfur atoms into benzotriazole-based p-type polymers to match with a benzotriazole-containing n-type small molecule: "The same-acceptor-strategy" to realize high open-circuit voltage. Adv Energy Mater, 2018, 8: 1801582

38 Tang A, Xiao B, Wang Y, et al. Simultaneously achieved high open-circuit voltage and efficient charge generation by fine-tuning charge-transfer driving force in nonfullerene polymer solar cells. Adv Funct Mater, 2018, 28: 1704507

39 Zhang Q, Xiao B, Du M, et al. $\mathrm{A}_{2}-\mathrm{A}_{1}-\mathrm{D}-\mathrm{A}_{1}-\mathrm{A}_{2}$ type non-fullerene acceptors based on methoxy substituted benzotriazole with three different end-capped groups for P3HT-based organic solar cells. J Mater Chem C, 2018, 6: 10902-10909

40 Xiao B, Geng Y, Tang A, et al. Controlling the cyano-containing $A_{2}$ segments in $A_{2}-A_{1}-D-A_{1}-A_{2}$ type non-fullerene acceptors to combine with a benzotriazole-based p-type polymer: "Same-acceptor-strategy" for high $V_{\text {OC }}$ organic solar cells. Sol RRL, 2019, 3 : 1800332

41 Jiang W, Yu R, Liu Z, et al. Ternary nonfullerene polymer solar cells with $12.16 \%$ efficiency by introducing one acceptor with cascading energy level and complementary absorption. Adv Mater, 2018, 30: 1703005

$42 \mathrm{Wu} \mathrm{Y}$, Bai $\mathrm{H}$, Wang Z, et al. A planar electron acceptor for efficient polymer solar cells. Energy Environ Sci, 2015, 8: 32153221

43 Holliday S, Ashraf RS, Wadsworth A, et al. High-efficiency and air-stable P3HT-based polymer solar cells with a new non-fullerene acceptor. Nat Commun, 2016, 7: 11585

44 Liu F, Zhang J, Zhou Z, et al. Poly(3-hexylthiophene)-based nonfullerene solar cells achieve high photovoltaic performance with small energy loss. J Mater Chem A, 2017, 5: 16573-16579

45 Wu J, Xu Y, Yang Z, et al. Simultaneous enhancement of three parameters of P3HT-based organic solar cells with one oxygen atom. Adv Energy Mater, 2018, 9: 1803012

46 Xiao $B$, Tang $A$, Zhang $Q$, et al. $A_{2}-A_{1}-D-A_{1}-A_{2}$ type non-fullerene acceptors with 2-(1,1-dicyanomethylene)rhodanine as the terminal groups for poly(3-hexylthiophene)-based organic solar cells. ACS Appl Mater Interfaces, 2018, 10: 34427-34434

47 Wang N, Yang W, Li S, et al. A non-fullerene acceptor enables efficient P3HT-based organic solar cells with small voltage loss and thickness insensitivity. Chin Chem Lett, 2019, 30: 1277-1281

48 Ye $\mathrm{P}$, Chen $\mathrm{Y}, \mathrm{Wu}$ J, et al. Combination of noncovalent conformational locks and side chain engineering to tune the crystallinity of nonfullerene acceptors for high-performance P3HT based organic solar cells. Mater Chem Front, 2019, 3: 64-69

49 Wadsworth A, Hamid Z, Bidwell M, et al. Progress in poly (3hexylthiophene) organic solar cells and the influence of its molecular weight on device performance. Adv Energy Mater, 2018, 8: 1801001

50 Qin Y, Uddin MA, Chen Y, et al. Highly efficient fullerene-free polymer solar cells fabricated with polythiophene derivative. Adv Mater, 2016, 28: 9416-9422
51 Li Z, He G, Wan X, et al. Solution processable rhodanine-based small molecule organic photovoltaic cells with a power conversion efficiency of 6.1\%. Adv Energy Mater, 2012, 2: 74-77

52 Kan B, Li M, Zhang Q, et al. A series of simple oligomer-like small molecules based on oligothiophenes for solution-processed solar cells with high efficiency. J Am Chem Soc, 2015, 137: 38863893

53 Deng D, Yang Y, Zou W, et al. Aromatic end-capped acceptor effects on molecular stacking and the photovoltaic performance of solution-processable small molecules. J Mater Chem A, 2018, 6: 22077-22085

54 Wang Z, Zhu X, Zhang J, et al. From alloy-like to cascade blended structure: Designing high-performance all-small-molecule ternary solar cells. J Am Chem Soc, 2018, 140: 1549-1556

55 Kim Y, Song CE, Moon SJ, et al. Rhodanine dye-based small molecule acceptors for organic photovoltaic cells. Chem Commun, 2014, 50: 8235-8238

56 Holliday S, Ashraf RS, Nielsen CB, et al. A rhodanine flanked nonfullerene acceptor for solution-processed organic photovoltaics. J Am Chem Soc, 2015, 137: 898-904

57 Hou J, Inganäs O, Friend RH, et al. Organic solar cells based on non-fullerene acceptors. Nat Mater, 2018, 17: 119-128

58 Yan C, Barlow S, Wang Z, et al. Non-fullerene acceptors for organic solar cells. Nat Rev Mater, 2018, 3: 18003

59 Fu H, Wang Z, Sun Y. Polymer donors for high-performance non-fullerene organic solar cells. Angew Chem Int Ed, 2019, 58: 4442-4453

60 Li C, Fu H, Xia T, et al. Asymmetric nonfullerene small molecule acceptors for organic solar cells. Adv Energy Mater, 2019, 9: 1900999

61 Xia T, Cai Y, Fu H, et al. Optimal bulk-heterojunction morphology enabled by fibril network strategy for high-performance organic solar cells. Sci China Chem, 2019, 62: 662-668

$62 \mathrm{Ma}$ D, Feng S, Zhang J, et al. Non-fullerene small molecular acceptors with a carbazole core for organic solar cells with high open-circuit voltage. Dyes Pigments, 2017, 146: 293-299

63 Li J, Yang J, Hu J, et al. The first thieno[3,4- $b]$ pyrazine based small molecular acceptor with a linear $\mathrm{A}_{2}-\mathrm{A}_{1}-\mathrm{D}-\mathrm{A}_{1}-\mathrm{A}_{2}$ skeleton for fullerene-free organic solar cells with a high $V_{\text {oc }}$ of $1.05 \mathrm{~V}$. Chem Commun, 2018, 54: 10770-10773

64 Suman, Gupta V, Bagui A, et al. Molecular engineering of highly efficient small molecule nonfullerene acceptor for organic solar cells. Adv Funct Mater, 2017, 27: 1603820

65 Radford CL, Hendsbee AD, Abdelsamie M, et al. Effect of molecular shape on the properties of non-fullerene acceptors: Contrasting calamitic versus 3D design principles. ACS Appl Energy Mater, 2018, 1: 6513-6523

66 Suman S, Bagui A, Datt R, et al. A simple fluorene core-based non-fullerene acceptor for high performance organic solar cells. Chem Commun, 2017, 53: 12790-12793

67 Zulfiqar A, Zhang J, Khan U, et al. Thermal-assisted $V_{\text {oc }}$ increase in an indenoindene-based non-fullerene solar system. Dyes Pigments, 2019, 165: 18-24

68 Wong KT, Chao TC, Chi LC, et al. Syntheses and structures of novel heteroarene-fused coplanar $\pi$-conjugated chromophores. Org Lett, 2006, 8: 5033-5036

69 Li Y, Gu M, Pan Z, et al. Indacenodithiophene: A promising building block for high performance polymer solar cells. J Mater Chem A, 2017, 5: 10798-10814

70 Bai H, Cheng P, Wang Y, et al. A bipolar small molecule based on 
indacenodithiophene and diketopyrrolopyrrole for solution processed organic solar cells. J Mater Chem A, 2014, 2: 778-784

71 Wang Y, Jia B, Qin F, et al. Semitransparent, non-fullerene and flexible all-plastic solar cells. Polymer, 2016, 107: 108-112

72 Tang LM, Xiao J, Bai WY, et al. End-chain effects of non-fullerene acceptors on polymer solar cells. Org Electron, 2019, 64: 16

73 Cao J, Shan T, Wang JK, et al. Stereoisomerism of ladder-type acceptor molecules and its effect on photovoltaic properties. Dyes Pigments, 2019, 165: 354-360

74 Zhang G, Xia R, Chen Z, et al. Overcoming space-charge effect for efficient thick-film non-fullerene organic solar cells. Adv Energy Mater, 2018, 8: 1801609

75 Chen S, Wang Y, Zhang L, et al. Efficient nonfullerene organic solar cells with small driving forces for both hole and electron transfer. Adv Mater, 2018, 30: 1804215

76 Yang L, Gu W, Yang Y, et al. A highly planar nonfullerene acceptor with multiple noncovalent conformational locks for efficient organic solar cells. Small Methods, 2018, 2: 1700330

77 Li QY, Xiao J, Tang LM, et al. Thermally stable high performance non-fullerene polymer solar cells with low energy loss by using ladder-type small molecule acceptors. Org Electron, 2017, 44: 217-224

78 Suman S, Siddiqui A, Keshtov ML, et al. New indolo carbazolebased non-fullerene $\mathrm{n}$-type semiconductors for organic solar cell applications. J Mater Chem C, 2019, 7: 543-552

79 Zhong W, Fan B, Cui J, et al. Regioisomeric non-fullerene acceptors containing fluorobenzo[c][1,2,5]thiadiazole unit for polymer solar cells. ACS Appl Mater Interfaces, 2017, 9: 3708737093

80 Zhong W, Cui J, Fan B, et al. Enhanced photovoltaic performance of ternary polymer solar cells by incorporation of a narrowbandgap nonfullerene acceptor. Chem Mater, 2017, 29: 81778186

81 Chen Y, Zhang Q, Du M, et al. Benzotriazole-based p-type polymers with thieno[3,2- $b]$ thiophene $\pi$-bridges and fluorine substituents to realize high $V_{\text {oc }}$. ACS Appl Polym Mater, 2019, 1: 906-913

82 Li T, Wang J, Chen H, et al. Nonfullerene acceptor with strong near-infrared absorption for polymer solar cells. Dyes Pigments, 2017, 137: 553-559

83 Ye $\mathrm{P}$, Chen $\mathrm{Y}, \mathrm{Wu}$ J, et al. Wide bandgap small molecular acceptors for low energy loss organic solar cells. J Mater Chem C, 2017, 5: 12591-12596

84 Zhang S, Ye L, Hou J. Breaking the $10 \%$ efficiency barrier in organic photovoltaics: Morphology and device optimization of well-known PBDTTT polymers. Adv Energy Mater, 2016, 6: 1502529

85 Xu S, Zhou Z, Fan H, et al. An electron-rich 2-alkylthieno[3,4-b] thiophene building block with excellent electronic and morphological tunability for high-performance small-molecule solar cells. J Mater Chem A, 2016, 4: 17354-17362

86 Wang P, Fan H, Zhu X. A 2-(trifluoromethyl)thieno[3,4-b]thiophene-based small-molecule electron acceptor for polymer solar cell application. Dyes Pigments, 2018, 155: 179-185

87 Xu H, Yang Y, Zhong C, et al. Narrow bandgap non-fullerene acceptor based on a thiophene-fused benzothiadiazole unit with a high short-circuit current density of over $20 \mathrm{~mA} \mathrm{~cm}{ }^{-2}$. J Mater Chem A, 2018, 6: 6393-6401

88 Ma Y, Zhang M, Tang Y, et al. Angular-shaped dithieno- naphthalene-based nonfullerene acceptor for high-performance polymer solar cells with large open-circuit voltages and minimal energy losses. Chem Mater, 2017, 29: 9775-9785

89 Xu YX, Chueh CC, Yip HL, et al. Improved charge transport and absorption coefficient in indacenodithieno[3,2- $b]$ thiophenebased ladder-type polymer leading to highly efficient polymer solar cells. Adv Mater, 2012, 24: 6356-6361

90 Jiang ZQ, Wang TT, Wu FP, et al. Recent advances in electron acceptors with ladder-type backbone for organic solar cells. J Mater Chem A, 2018, 6: 17256-17287

$91 \mathrm{Qu} \mathrm{J}, \mathrm{Mu} \mathrm{Z}$, Lai $\mathrm{H}$, et al. Alkyl chain end group engineering of small molecule acceptors for non-fullerene organic solar cells. ACS Appl Energy Mater, 2018, 1: 4724-4730

92 Song J, Xue X, Fan B, et al. A novel bifunctional A-D-A type small molecule for efficient organic solar cells. Mater Chem Front, 2018, 2: 1626-1630

93 Tang C, Chen SC, Shang Q, et al. Asymmetric indenothiophenebased non-fullerene acceptors for efficient polymer solar cells. Sci China Mater, 2017, 60: 707-716

94 Bai W, Xu X, Li Q, et al. Efficient nonfullerene polymer solar cells enabled by small-molecular acceptors with a decreased fused-ring core. Small Methods, 2018, 2: 1700373

95 Lee J, Singh R, Sin DH, et al. A nonfullerene small molecule acceptor with 3D interlocking geometry enabling efficient organic solar cells. Adv Mater, 2016, 28: 69-76

96 Meng D, Fu H, Xiao C, et al. Three-bladed rylene propellers with three-dimensional network assembly for organic electronics. J Am Chem Soc, 2016, 138: 10184-10190

97 Zhang A, Li C, Yang F, et al. An electron acceptor with porphyrin and perylene bisimides for efficient non-fullerene solar cells. Angew Chem Int Ed, 2017, 56: 2694-2698

98 Ma S, Fu Y, Ni D, et al. Spiro-fluorene based 3D donor towards efficient organic photovoltaics. Chem Commun, 2012, 48: 1184711849

99 Qiu N, Yang X, Zhang H, et al. Nonfullerene small molecular acceptors with a three-dimensional (3D) structure for organic solar cells. Chem Mater, 2016, 28: 6770-6778

100 Tan H, Long Y, Zhang J, et al. Spirobifluorene-cored wide bandgap non-fullerene small molecular acceptor with 3D structure for organic solar cells. Dyes Pigments, 2019, 162: 797-801

101 Zhang G, Yang G, Yan H, et al. Efficient nonfullerene polymer solar cells enabled by a novel wide bandgap small molecular acceptor. Adv Mater, 2017, 29: 1606054

$102 \mathrm{Xu} \mathrm{X}, \mathrm{Bi} \mathrm{Z}, \mathrm{Ma} \mathrm{W}$, et al. Highly efficient ternary-blend polymer solar cells enabled by a nonfullerene acceptor and two polymer donors with a broad composition tolerance. Adv Mater, 2017, 29: 1704271

103 Wen X, Xiao B, Tang A, et al. Wide band gap non-fullerene small molecular acceptors containing spirobifluorene and benzotriazole with three different end-capped groups for P3HT-based organic solar cells. Chin J Chem, 2018, 36: 392-398

104 Lin K, Xie B, Wang Z, et al. Star-shaped electron acceptors containing a truxene core for non-fullerene solar cells. Org Electron, 2018, 52: 42-50

105 Tang D, Wan J, Xu X, et al. Naphthobistriazole-based wide bandgap donor polymers for efficient non-fullerene organic solar cells: Significant fine-tuning absorption and energy level by backbone fluorination. Nano Energy, 2018, 53: 258-269

106 Guo Y, Zhang A, Li C, et al. A near-infrared porphyrin-based electron acceptor for non-fullerene organic solar cells. Chin 
Chem Lett, 2018, 29: 371-373

107 Lee T, Eom Y, Song CE, et al. Simple bithiophene-rhodaninebased small molecule acceptor for use in additive-free nonfullerene OPVs with low energy loss of $0.51 \mathrm{eV}$. Adv Energy Mater, 2019, 9: 1804021

108 Kim J, Song CE, Lee SK, et al. Synthesis and characterization of small molecules with isoindigo substituted dye end groups. J Nanosci Nanotechnol, 2016, 16: 8737-8740

109 Privado M, Cuesta V, de la Cruz P, et al. Efficient polymer solar cells with high open-circuit voltage containing diketopyrrolopyrrole-based non-fullerene acceptor core end-capped with rhodanine units. ACS Appl Mater Interfaces, 2017, 9: 11739-11748

110 Privado M, Cuesta V, de la Cruz P, et al. Tuning the optoelectronic properties for high-efficiency $(>7.5 \%)$ all small molecule and fullerene-free solar cells. J Mater Chem A, 2017, 5: 1425914269

111 Privado M, de la Cruz P, Biswas S, et al. A non-fullerene all small molecule solar cell constructed with a diketopyrrolopyrrole-based acceptor having a power conversion efficiency higher than $9 \%$ and an energy loss of $0.54 \mathrm{eV}$. J Mater Chem A, 2018, 6: 1171411724

112 Peng W, Zhang G, Shao L, et al. Simple-structured small molecule acceptors constructed by a weakly electron-deficient thiazolothiazole core for high-efficiency non-fullerene organic solar cells. J Mater Chem A, 2018, 6: 24267-24276

113 Liu Y, Liu G, Xie R, et al. A rational design and synthesis of crossconjugated small molecule acceptors approaching high-performance fullerene-free polymer solar cells. Chem Mater, 2018, 30: 4331-4342

$114 \mathrm{Mu}$ C, Liu P, Ma W, et al. High-efficiency all-polymer solar cells based on a pair of crystalline low-bandgap polymers. Adv Mater, 2014, 26: 7224-7230

115 Gao L, Zhang ZG, Xue L, et al. All-polymer solar cells based on absorption-complementary polymer donor and acceptor with high power conversion efficiency of $8.27 \%$. Adv Mater, 2016, 28: 1884-1890

116 Chen D, Yao J, Chen L, et al. Dye-incorporated polynaphthalenediimide acceptor for additive-free high-performance all-polymer solar cells. Angew Chem Int Ed, 2018, 57: 4580-4584

Acknowledgements The authors thank the financial support from the National Natural Science Foundation of China (21704030 and 21602115).

Author contributions $\quad \mathrm{Li} \mathrm{Z}$ and Zhao D conceived this work. Liu $\mathrm{H}$ wrote the original draft. All authors contributed to the final version of the manuscript.

Conflict of interest The authors declare no conflict of interest.

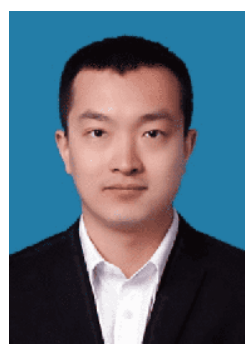

Hongtao Liu received his MSc degree in polymer chemistry and physics from Jiangxi Science and Technology Normal University in 2017. He is currently a $\mathrm{PhD}$ candidate under the supervision of Prof. Zhong'an Li in the School of Chemistry and Chemical Engineering at Huazhong University of Science and Technology. His research interest includes the design and synthesis of novel non-fullerene acceptors for organic solar cells.

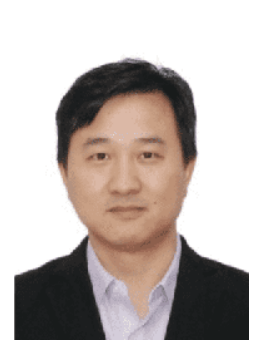

Zhong'an Li received his $\mathrm{PhD}$ degree in materials physics and chemistry from Wuhan University under the supervision of Prof. Zhen Li in 2009. From 2009 to 2016, he worked with Prof. Alex Jen at the University of Washington as a postdoctoral research associate. He started his independent career in 2016 in the School of Chemistry and Chemical Engineering at Huazhong University of Science and Technology. His research interest focuses on the design, synthesis and characterization of new organic/polymeric

optoelectric materials.

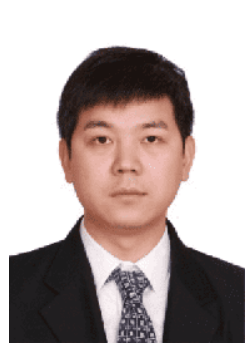

Dongbing Zhao received his $\mathrm{PhD}$ degree in organic chemistry from Sichuan University under the supervision of Prof. Jingsong You in 2012. From 2012 to 2016, he was a postdoctoral research fellow in organic chemistry at Muenster University, in polymer chemistry at Cornell University and in material science at the University of Washington. He started his independent career in 2016 in the College of Chemistry at Nankai University. His research interest includes organic synthesis, $\pi$-conjugated materials, bio-images and organic solar cells.

\section{基于饶丹宁的有机太阳能电池非富勒烯受体}

刘宏涛, 李忠安 ${ }^{1 *}$, 赵东兵 ${ }^{2 *}$

摘要 近年来, 有机太阳能电池非富勒烯受体(NFAs)的研究取得了 重大进展, 且在叠层器件中实现了超过 $17 \%$ 的光电转换效率( $\mathrm{PCE}$ ). 目前, 具有线型稠合受体-供体-受体(A-D-A)结构的NFAs因其优异 的合成灵活性和高光伏性能而受到了广泛关注. 其中, 饶丹宁染料 是构建这类A-D-A型NFAs的最为常见的吸电子受体单元, 且所得 单结太阳能电池的PCE已超过 $10 \%$. 尤为重要的是, 饶丹宁受体与 众所周知的P3HT供体结合时表现出十分优异的相容性，进而获得 了7\%的PCE. 因此, 本文总结了饶丹宁非富勒烯受体材料的研究进 展, 侧重于讨论其分子设计策略, 旨在帮助读者更好的理解这类非 富勒烯受体的构性关系. 